\title{
SEED DISPERSER EFFECTIVENESS: THE QUANTITY COMPONENT AND PATTERNS OF SEED RAIN FOR PRUNUS MAHALEB
}

\author{
Pedro Jordano ${ }^{1,3}$ And Eugene W. Schupp ${ }^{2}$ \\ ${ }^{1}$ Estación Biológica de Doñana, CSIC, Apdo. 1056, E-41080 Sevilla, Spain \\ ${ }^{2}$ Department of Rangeland Resources and The Ecology Center, Utah State University, Logan, Utah 84322-5230, USA, and \\ Estación Biológica de Doñana, CSIC, Apdo. 1056, E-41080 Sevilla, Spain
}

\begin{abstract}
In this paper we analyze the seed dispersal stage of the Prunus mahaleb-frugivorous bird interaction from fruit removal through seed delivery within the context of disperser effectiveness. The effectiveness of a frugivorous species as a seed disperser is the contribution it makes to plant fitness. Effectiveness depends on the quantity of seed dispersed ("quantity component") and the quality of dispersal provided each seed ("quality component"). For the main frugivores, we studied abundance, visitation rate, and feeding behavior, the major variables influencing the quantity component of effectiveness, and the postforaging microhabitat use and resultant seed shadows, which set the stage for postdispersal factors that will influence the quality component of effectiveness.

Legitimate seed dispersers (SD) swallowed fruits whole and defecated or regurgitated intact seeds; pulp consumers (PC) pecked fruits to obtain pulp and dropped seeds to the ground, but some species occasionally dispersed seeds (PCSD species). Overall numbers of fruits removed (i.e., handled) by avian frugivores were similar in the two study years; however, the estimated percentage of seeds dispersed differed significantly, with lower relative dispersal success in the year with greater relative abundance of PC species. Similar numbers of seeds were dispersed in the two years despite nearly a fourfold difference in number of fruits produced. Fruit crop size explained $>80 \%$ variance in the number of seeds dispersed per tree.
\end{abstract}

A total of 38 species of birds were recorded during censuses, with frugivores representing $68.8 \%$ of them; the relative representation of SD, PC, and PCSD species was $42.2 \%, 17.2 \%$, and 9.4\%, respectively. Individual trees showed extensive variation in visitation rates, ranging from 0.3 to 41.6 visits/10 $\mathrm{h}$ in any year. The main visitors were the SD species Phoenicurus ochruros (10.8 visits/10 h), Turdus viscivorus (9.2 visits/10 h), Erithacus rubecula (3.5 visits/10 h), and Sylvia communis (2.6 visits/10 h); and the PC species Fringilla coelebs (16.7 visits/10 h) and Parus ater (4.7 visits/10 h).

Species with large quantity components of effectiveness typically had either high visit or high feeding rates, combined with high probability of dispersing a handled seed. Variation among species in fruit-handling behavior, however, was the main factor influencing variation in the quantity component. Visit rate in turn was influenced largely by local abundance. No single frugivore trait, however, can adequately estimate the quantity component of disperser effectiveness. A "gulper"/"masher" dichotomy helps explain differences in fruit handling among major frugivore types and shows many correlates with other aspects of frugivore activity that ultimately influence the quantity component.

Most species showed marked preferences for microhabitats with plant cover, especially $P$. mahaleb, midheight shrubs, and Pinus ( $86.1 \%$ of the departure flights) and avoided open microhabitats. Most flights were over short distances $(77.5 \%$ to perches located within $30 \mathrm{~m})$. Among the main frugivores, $40.3 \%$ of the exit flights were to perches $>15 \mathrm{~m}$ away from the feeding tree, but only $18.5 \%$ of these flights were to perches $>15 \mathrm{~m}$ from any $P$. mahaleb. Covered microhabitats received significantly more seeds $\left(39.3 \pm 5.0\right.$ seeds dispersed $/ \mathrm{m}^{2}, 1988$ $[$ mean $\pm 1 \mathrm{sE}] ; 31.7 \pm 5.9$ seeds dispersed $\left./ \mathrm{m}^{2}, 1989\right)$ than open microhabitats $\left(2.8 \pm 0.7 \mathrm{seeds} \mathrm{dispersed} / \mathrm{m}^{2}\right.$, $1988 ; 1.8 \pm 0.4$ seeds dispersed $\left./ \mathrm{m}^{2}, 1989\right)$.

The potential contribution of each bird species to the seed rain in each microhabitat was estimated from the number of visits recorded, the mean number of seeds dispersed per visit, and the proportion of exit flights to each microhabitat. Microhabitats differed strongly in the proportions of seeds delivered by the main frugivores, and bird species also differed in the proportions of seeds delivered to a given microhabitat. The seed rain to covered microhabitats was delivered by a more heterogeneous assortment of species than the seed rain to open sites. The resulting seed shadow was a complex result of the interaction between movement patterns of a suite of bird species differing both in the quantity of seed dispersed and microhabitat preferences and in the landscape distribution of these microhabitat patches. This seed shadow was extremely nonrandom due both to a strong overall preference by most of the birds for the relatively scarce covered microhabitats and to species-specific preferences for particular types of covered microhabitats. Different microhabitat types not only received variable amounts of dispersed seed, but also differed in the number and identity of disperser species contributing to that seed rain.

Key words: avian frugivory; fruit removal; fruit size; Mediterranean scrubland; mutualism; plant demography; seed dispersal; seed rain; Spain; Sylvia; Turdus.

Manuscript received 2 October 1998; revised 21 April 1999; accepted 8 June 1999.

${ }^{3}$ E-mail: jordano@ cica.es 


\section{INTRODUCTION}

The effectiveness of frugivores as seed dispersal agents of their food plants depends on both the quantity of dispersal, or the amount of seed dispersed, and the quality of dispersal, or the probability seeds are deposited unharmed in sites with high prospects for establishment. Ultimately, disperser effectiveness is the contribution a disperser makes to plant fitness, ideally measured as the number of reproductive adults recruited through the activity of a dispersal agent (Schupp 1993), and both quantity and quality components of frugivore behavior influence it in measurable ways (Herrera and Jordano 1981). Even with the immense amount of information on seed dispersal by frugivorous animals obtained during the last 20 years, we still lack a clear picture of how effects of frugivore activity translate into demographic and evolutionary consequences for the plants (Howe 1990, Jordano 1992, Herrera et al. 1994, Schupp 1995, Schupp and Fuentes 1995). A central objective of this paper, and a first step in this direction, is to document the immediate consequences of frugivore activity for plant recruitment, specifically to assess quantitatively the landscape pattern of seed delivery by individual frugivore species. The quantity component of disperser effectiveness provides a unifying theme for addressing this objective.

The net result of frugivore activity is fruit removal, which may or may not result in seed dispersal away from the parent. Fruit removal in this study is equated with fruit handling, and includes any successful or unsuccessful (e.g., fruit is too large to swallow) attempt by a frugivore to consume fruit pulp, whether or not the fruit is detached from the peduncle. Removal generally leads to successful seed dispersal if done by legitimate seed dispersers, or seed loss if done by pulp/ seed consumers that damage seeds or drop them beneath the parent canopy. Whether fruit removal leads to successful seed dispersal (away from the parent) thus depends largely on frugivore feeding behavior, fruit processing, and postfeeding movements. Immediate influences on seed fate depend on whether or not seeds are damaged during mandibulation and digestion (Levey 1987, Corlett and Lucas 1990), and whether or not seeds are dropped beneath the parent canopy (Howe and Vande Kerckhove 1981, Wheelwright 1991). Lasting influences on seed and seedling survivorship depend on the types of microsites where seeds are delivered. As the movement patterns of frugivores are frequently nonrandom relative to available microhabitats, and microhabitats frequently differ substantially in abiotic (e.g., light levels, water availability, soil texture) and biotic (e.g., competition, seed predator and herbivore pressure) conditions, differences in postremoval behavior of frugivores should have deferred effects on the recruitment of new plants (Schupp 1993, Schupp 1995). Whether or not frugivore activity results in successful recruitment thus depends on fruit processing, disperser movement and microhabitat use, and biotic and abiotic influences on survivorship of seeds, seedlings, and saplings. Categorization and quantification of these aspects and outcomes of frugivore foraging is thus a prerequisite for assessing disperser effectiveness.

Two stages can therefore be envisioned with respect to the consequences of the interactions between frugivores and their food plants. First, the dispersal stage encompasses the visit to the fruiting tree and the postfeeding sequence of activities resulting in seed delivery (frugivore-generated seed rain). This stage is directly influenced by frugivore activity. Second, the postdispersal stage includes the sequential phases of seed stay in the soil, germination, early seedling establishment, and seedling and sapling growth and survival (regeneration). Fate at this stage is also influenced by initial frugivore activity, but indirectly; that is, fate is a delayed consequence of the pattern of seedfall generated by frugivore activity. The complete sequence of steps in this process has seldom been considered for any species (but see Howe et al. 1985, Reid 1989, Howe 1993, Murphy et al. 1993, Herrera et al. 1994, Jordano and Herrera 1995, Schupp 1995, Wenny and Levey 1998). Even for the well-documented seed dispersal stage, we lack a clear understanding of how its components (visitation rate, visit length, feeding rate, fruit handling, and seed processing) influence the quantity component of effectiveness - the amount of seeds dispersed by a given frugivore species (Schupp 1993). An integrative approach to seed dispersal that fully investigates both dispersal and postdispersal stages of the interaction from the perspective of disperser effectiveness is a powerful approach for developing an understanding of the ecological and evolutionary consequences of plant-frugivore mutualisms.

Although the concept of disperser effectiveness was developed as a framework for evaluating contributions of individual disperser species to plant fitness, it can be viewed from a variety of perspectives (Schupp 1993). In particular, a thorough investigation of the quantity component of seed dispersal should consider not only the quantity of seed dispersed by individual frugivore species, but also the quantity of seeds dispersed from individual trees. The absolute numbers of seeds removed by frugivores (removal success) and dispersed away from the parent's canopy by legitimate dispersers (dispersal success) are ultimately limited by the number of ripe fruits produced by a plant. Recent studies have suggested that frugivore activity might limit fruit removal and seed dispersal (Davidar and Morton 1986, Herrera 1988, Jordano 1989, Carr 1992, Herrera et al. 1994, Laska and Stiles 1994), so that actual dispersal success is frequently less than this maximum. If, for example, visitation by fruit and seed predators is frequent, or visitation by legitimate seed dispersers is infrequent relative to fruit crop size, individual plants may disperse only a fraction of the seeds 
produced. Thus, plants differ not only in the absolute number of seeds removed and dispersed, but also in the proportion of the seed crop removed (relative removal success) and dispersed (relative dispersal success). Both absolute and relative measures are relevant for understanding seed dispersal systems. To the extent that seed dispersal is beneficial, absolute dispersal success can be viewed as a correlate of parental plant fitness. In contrast, independent of absolute dispersal success, relative dispersal success can be considered a measure of the extent to which a plant attains its potential fitness.

Both absolute and relative dispersal success depend on a number of factors "intrinsic" (plant size, fruit set, fruit crop size, fruit size, pulp/seed ratio) and "extrinsic" (neighborhood of conspecifics, surrounding habitat structure, availability of other fruit, etc.) to the plant. Understanding the influences of these intrinsic (e.g., the predispersal flower and fruit loss that limits fruit production [Jordano 1989]) and extrinsic (e.g., influence of surrounding vegetation on visitation [Herrera and Jordano 1981, Traveset 1994]) factors on both absolute and relative dispersal success is thus central to understanding of the role of frugivores as determinants of dispersal success. For example, variation among trees in the total number of seeds dispersed could be simply due to differences in crop size, or, if legitimate seed dispersers preferentially visit certain trees, to differences in relative dispersal success (Davidar and Morton 1986, Jordano 1989, Carr 1992, Herrera et al. 1994).

In this study we quantify the seed dispersal stage of the Prunus mahaleb-frugivorous bird interaction from fruit removal to seed delivery. The focus is on the quantity component of seed disperser effectiveness and its correlates, and on the microhabitat pattern of seed rain created by individual disperser species. In order to develop a more complete quantitative understanding of seed dispersal, we also consider the quantity of seed dispersed by individual trees and the intrinsic and extrinsic factors influencing it. Deferred consequences of seed dispersal for seed survival and germination and seedling and sapling establishment will be presented in subsequent papers. The primary specific issues addressed here are: (1) Do frugivore species differ predictably in visitation patterns, number of fruits consumed, probability of dispersing a handled seed, and number of seeds dispersed per visit? (2) How do these variables co-vary across species in this assemblage? (3) How do these variables affect the quantity component of $P$. mahaleb seed dispersal by individual species? (4) Are differences among dispersers consistent between years? (5) Do dispersers in this assemblage differ predictably in the types of microsites to which they deliver seeds? and (6) Do these differences generate a predictable seed shadow?

\section{Methods}

Definitions

Frugivory types.-Four main types of frugivorous birds that visit $P$. mahale $b$ can be distinguished based on foraging mode and immediate consequences for seed dispersal. Seed dispersers (SD, hereafter) swallow the fruits whole and defecate or regurgitate intact seeds. Pulp consumers (PC) peck the fruit to obtain pulp pieces either without detaching it from the peduncle or, after plucking, by tearing off the pulp while the fruit is in the bill or held against a perch. In both cases the seed is eventually dropped to the ground. Pulp consumer-dispersers (PCSD) are PC species that in rare instances pluck the fruit and leave the tree to eat the pulp on another perch, thus performing infrequent dispersal of seeds without ingestion. Finally, seed predators (SP) feed on the seed contents and always damage the seeds. Additional details on feeding behavior of frugivores visiting $P$. mahaleb can be found in Herrera and Jordano (1981), Guitián et al. (1992), and Jordano (1994); see also Snow and Snow (1988).

Fruit removal and seed dispersal.-We scored a fruit as removed whenever a frugivorous bird handled it. Removal actually implies plucking the fruit from its peduncle, but we also include those instances when pieces of the pulp are torn off the fruit by PC species without separating it from the peduncle. Such fruits rapidly desiccate and are highly unlikely to be consumed by a legitimate disperser; instead, they eventually fall to the ground. Fruit removal may or may not result in dispersal of the enclosed seed away from the parent's canopy. Thus, the initial fates of individual ripe fruits on $P$. mahaleb can be categorized as: (1) "removed," when a fruit is handled by a frugivorous bird, whether it is detached from the peduncle or not; (2) "ripe damaged," when invertebrates damage a ripe fruit; or (3) "ripe desiccated," when fruits are not removed and, eventually, the pulp desiccates and the fruit falls to the ground beneath the parent. Fruit removal can result in seed dispersal away from the parent plant when removal is by SD species and, on rare occasions, by PCSD species. In contrast, damage by invertebrates and fruit removal by PC and PCSD species that results in the fruit immediately or eventually falling beneath the parent do not lead to seed dispersal.

We refer to the number of fruits removed from a tree as fruit removal success. Similarly, seed dispersal success is the estimated number of seeds dispersed away from the tree's canopy; only a fraction of fruit removal results in seed dispersal. Relative removal or dispersal success for a tree is simply the proportion of fruits removed, or seeds dispersed, relative to the initial crop of ripe fruits.

\section{Study area}

This study was conducted during 1988-1989 in the Reserva de Navahondona-Guadahornillos (Parque Nat- 
ural de las Sierras de Cazorla, Segura y las Villas, Jaén province, southeastern Spain). The study area was located in Nava de las Correhuelas, a site in the highlands of the park, at $1615 \mathrm{~m}$ elevation. The main study site extends over $\sim 100$ ha and includes both deep cool soils and rocky, exposed slopes. Deciduous vegetation, including Crataegus monogyna, Prunus mahaleb, Lonicera arborea, Berberis hispanica, Daphne laureola, Rosa canina, and Acer granatense, occupies the deep soils. Adjacent rocky slopes are dominated by open pine forest (Pinus nigra, subsp. salzmannii) with Juniperus communis, J. phoenicea, J. sabina, and scattered Taxus baccata (Valle et al. 1989). The climate is of Mediterranean montane type. Rainfall averages 1527 $\mathrm{mm}$ and is concentrated in autumn-winter. Only $9 \%$ of total annual precipitation falls during June-September, the main ripening season for $P$. mahale $b$ fruits. Average temperatures for coldest and hottest months are $2.9^{\circ} \mathrm{C}$ and $22.5^{\circ} \mathrm{C}$, respectively. Snowfalls are frequent from November to March.

The study of fecundity variation, seed removal success, bird censuses, and feeding observations was carried out on trees growing scattered throughout this main study site. Within this larger study area, we set up a $90 \times 120 \mathrm{~m}$ intensive study plot for observational work on microhabitat patterns of postfeeding bird flights and of seed rain. Although restricting these observations to a small plot may limit the generality of the results, it is necessary in order to adequately characterize flight and seedfall patterns relative to microhabitat availability. Additional observational and experimental work associated with a long-term study of postdispersal processes (germination, seed predation, and seedling and sapling survival and growth) to be reported later is also taking place in this plot.

\section{Plant natural history}

Prunus mahaleb, the Saint Lucie's or Mahoma's cherry, is a small tree (2-10 $\mathrm{m}$ in height) that grows scattered at mid-elevations (1250-1900 m) in the southeastern Spanish mountains, through the Pyrenees and central and eastern Europe to Ukraine, and from Morocco through Syria to west-central Asia (Webb 1968, Ceballos and Ruiz 1979). Detailed information on the pollination biology has been published elsewhere (Jordano 1993b; also see Guitián 1993, Guitián et al. 1993). Fruits are drupes, black when ripe, $8.0 \pm$ $4.4 \mathrm{~mm}$ long (mean $\pm 1 \mathrm{SE}$ ) and $8.3 \pm 0.5 \mathrm{~mm}$ wide $(N=20)$, and with a sugary, water-rich pulp (Herrera and Jordano 1981). Chemical analyses of the fruit pulp reported by these authors yielded $3.2 \%$ crude fat, $2.8 \%$ crude protein, $6.3 \%$ ash, $5.7 \%$ fiber, and $82.0 \%$ soluble carbohydrates. Fruit crops of individual trees usually range between 700 and 30000 fruits.

Information on interactions of $P$. mahaleb with frugivorous animals that consume fruits and disperse seeds has been reported by Herrera and Jordano (1981), Herrera (1989), Guitian et al. (1992), and Jordano
(1994). At least 28 bird species, four mammals, and one lizard have been recorded feeding on the fruits at our site (P. Jordano and E.W. Schupp, personal observations).

\section{Trees}

We assessed fruit removal and seed dispersal in a sample of 21 trees. These were a stratified sample of the trees in an initial census of 120 adult trees scattered through the main study site. The trees in the sample grow in four large patches over $\sim 10$-ha area that slightly overlaps the intensive study plot. The range of growing conditions in the overall site are represented in this area. Crop sizes of final-sized fruits were estimated by direct counts of all marked plants during the last two weeks of July in 1988 and 1989 (see Jordano 1994, 1995 , for a detailed account of the method). During this period fruits start to ripen, but massive fruit removal has not yet begun. We used weekly counts of individual fruits on marked branches to estimate the standing crops and proportions of unripe, ripe, and damaged fruits, as well as predispersal loss of fruits (see Jordano 1987a, Herrera 1988, Jordano 1989, Jordano 1994 for detailed description of the methods). Depending on tree size, up to five branches per tree were randomly selected in a stratified manner, with one branch selected at each of up to five positions regularly spaced around the canopy. The total number of fruits followed in marked branches were 3560 and 3780 fruits in 1988 and 1989, respectively. This repeated counts of branches was used to estimate the fraction of the fruit crop ripened, removed by frugivores, and potentially dispersed.

Fruit loss estimates (fruits considered unsuitable for frugivorous birds) for each tree were scored during the periodic branch counts as ripe desiccated (DES), ripe damaged by invertebrates (DAM; invertebrate damage to ripe fruits of $P$. mahaleb is extremely rare at the site and was recorded only on a few marked fruits), unripe desiccated (UNR), or pecked with pulp remains attached (PEC). The proportion of fruits removed was calculated by: [MARK - (DES + DAM + UNR)]/ MARK, where MARK is the number of fruits initially marked on the tree. Any fruit not entering the DES, DAM, or UNR category by the end of the survey period was clearly missing (detached from its peduncle) and was considered removed, as were PEC fruits.

In order to estimate seed dispersal we first estimated the maximum proportion of seeds potentially dispersed from the tree (maximum potentially removed by legitimate seed dispersers) as: [MARK - (DES + DAM + UNR + PEC)]/MARK. These seed dispersal estimates from branch counts will overestimate dispersal, however, because fruits plucked from peduncles by PC species, and most of those plucked by PCSD species, are not taken away from the tree, but are dropped beneath the parent instead. Consequently, not all missing fruits have been dispersed. To correct this overestimation we 
proceeded as follows. Just after the 1988 fruiting season we counted fruit and seed remains on the ground, beneath the canopies of sampled trees. Between three and eight, $0.5 \times 0.5 \mathrm{~m}$ quadrats were sampled per tree depending on tree size (7.5-18.5\% of the canopy area), and all fruit and/or seed remains (except dispersed seeds in regurgitations or feces, that likely originate from other trees) were recorded and counted. These quadrats were located at regularly spaced locations beneath the canopy, approximately midway between the trunk and the canopy edge. Fruit and seed removal by rodents and/or ants is scarce during this period (P. Jordano, personal observation), so that repeated counts of fruit and seed in unprotected ground may provide reasonably adequate estimates of seed and fruit fall. The number of DES, DAM, UNR, and PEC fruits were counted in each ground sample, and a figure for the whole tree was estimated by extrapolating the sampled surface to the area of the canopy projection. We then subtracted this figure from the total crop size to obtain the estimated numbers of fruits consumed and seeds dispersed. This is analogous to seed trap methods (see Jordano 1994, 1995) and was used to assess consistency in the estimates of fruit loss and of seed removal derived from branch counts, and to assess the reliability of our estimates of the proportions of seeds leaving the trees derived from branch counts.

As expected, PEC figures were underestimated in the branch counts (due to the fact that some missing fruits here were being taken by PC species that drop the partially consumed fruit and seeds beneath), and the use of branch counts alone would overestimate seed dispersal success. The proportion of PEC fruits estimated from ground counts was, however, significantly correlated with the proportion estimated from branch counts $\left(R^{2}=0.801, P<0.01\right)$. For individual trees in 1988, we used the PEC estimate derived from ground counts, together with the DES, UNR, and DAM figures obtained from branch counts, to estimate seed dispersal. For 1989 we applied the 1988 regression to the PEC values obtained from the branch counts and used this estimate of the proportion of PEC loss in the calculation of seed dispersal success for each tree (Jordano 1994).

We sampled intact ripe fruits directly from branches before extensive fruit consumption had started in the area. Fruits were measured (maximum length and cross diameter, to the nearest $0.05 \mathrm{~mm}$, with digital calipers), and weighed to obtain masses of both pulp and seed ( $\operatorname{sum}=$ whole fruit).

\section{Birds}

Censuses and feeding records.-We censused line transects of fixed width (120 m, between 715 and 775 $\mathrm{m}$ length) on three days per week (not consecutive) during the two study seasons to determine the abundance of birds (expressed as number of birds per kilometer of census) and obtain feeding records on fruits ( 1 feeding record $=$ consumption of 1 fruit; Snow and
Snow 1988). Total sampling effort was $4.3 \mathrm{~km}(N=6$ censuses) and $6.2 \mathrm{~km}$ ( $N=8$ censuses), with 560 and 673 individuals censused in 1988 and 1989, respectively. The number of feeding records was 2854 for the two years pooled. The dataset included those records reported by Jordano (1994) and feeding records on four trees growing within the intensive study plot. See Jordano $(1993 a, 1994)$ for details of the census methods.

Feeding observations.-We conducted direct watches at a total of 15 trees in $1988(N=99.6 \mathrm{~h}$ observation, 190.3 tree-hours); and 12 trees in $1989(N=82.9 \mathrm{~h}$ observation, 165.0 tree-hours). Tree-hours were greater than total hours because more than one tree could be observed at one time in some cases. Observation effort was allocated among trees so that each tree was observed on multiple days and at least once during each of the following periods of the day: 0530-0800, 10001400, and after 1600. Most observations, however, were between 0630-1500 Greenwich Mean Time (GMT). Observation periods lasted $1 \mathrm{~h}$, and all individuals visiting the tree were identified to species, when possible, and the time of the visit recorded.

We intensively studied the behavior of birds while feeding on fruits either during the direct watches or during additional observation periods. For each bird sighted, the following data were recorded whenever possible: (1) total time spent at the tree, (2) number of fruits handled ("removed" by our definition), (3) number of fruits swallowed, (4) number of fruits dropped, (5) number of fruits touched but not detached from the peduncle, (6) number of times the bird moved during the observation sequence (number of "moves"), (7) total time stopped during the observation sequence, (8) number of fruits carried away from the tree in the bill, and (9) for bird species eating only pulp, whether the pulp was pecked from the fruit without detaching it from its peduncle or was stripped from the seed while holding it in the bill (and the seed dropped). Birds could not always be observed for complete visits to the trees; in these instances ("partial" visits, hereafter), the record was omitted for the computation of number of fruits and seeds taken per visit, but was used to estimate feeding rates (e.g., fruits and seeds per minute).

Visitation rates, postfeeding flights, and the seed shadow.-We intensively studied visitation patterns to four trees located in the intensive study plot to attempt to quantify the number of seeds potentially reaching different microhabitat types by means of delivery by different frugivore species. Thus, for this subset of the trees we simultaneously studied removal success, bird visitation rates, and feeding behavior (numbers of fruits handled, ingested, and dropped), and the type of microhabitat where birds first perched after feeding on the fruits and leaving the tree, as well as the distance between the tree a bird fed in and the first landing perch after leaving the feeding tree. We used the following intervals: $0,<5 \mathrm{~m}, 5-<15 \mathrm{~m}, 15-<30 \mathrm{~m}, 30-<50 \mathrm{~m}$, $50-<100 \mathrm{~m}$, and $\geq 100 \mathrm{~m}$. When a bird stayed in the 
tree $>15$ min after feeding we coded the microhabitat destination as $P$. mahaleb and the distance as $0 \mathrm{~m}$ because of the high likelihood that the seed had been regurgitated or defecated in this time, and thus not dispersed. We also included other sporadic observations of birds leaving trees within the plot after consuming fruit. These incidental data were used to increase the sample size for analysis of postfeeding behavior of individual species, not in any comparisons among species.

To study visitation rates to each of these four focal trees we sampled a total of 16 tree-days per year, with observations carried out during five periods of the day: 0530-0800, 0800-1000, 1000-1200, 1200-1600, and after 1600 GMT. Watching periods of variable duration were assigned to each interval and all four trees received a similar observation effort at different times of the day. The total observation time was $107.3 \mathrm{~h}$.

We defined nine types of microhabitat based on both the type of soil and vegetation cover: (1) "P. mahaleb," on or beneath a conspecific tree; (2) "low shrubs," including Juniperus communis, Berberis hispanica, and Rhamnus spp. and juveniles of the taller shrub species < $1 \mathrm{~m}$ in height; (3) "midheight shrubs," including Crataegus monogyna, Rosa canina, and Lonicera arborea; (4) "high trees," Pinus nigra subsp. salzmannii; (5) "high trees above low shrubs," $P$. nigra with J. communis or B. hispanica undergrowth; (6) "deep soil," with thick cover of herbaceous vegetation; (7) "gravelly soil," with gravel and cobble $<0.06 \mathrm{~m}^{2}$ surface area and sparse herbaceous cover; (8) "stones on soil," on or within $25 \mathrm{~cm}$ of a larger $(0.06-<0.25$ $\mathrm{m}^{2}$ ) generally elevated rock that is usually associated with gravelly soil; and (9) "rock," boulders and rock substrate $>0.25 \mathrm{~m}^{2}$ (generally much greater), and with fissures. We were unable to adequately distinguish flights to microhabitats 4 and 5 when observing birds flying a long distance. Thus, we recorded all exit flights to high trees for each species and multiplied these figures by the relative proportions of 4 and 5 in the habitat to estimate their relative use by each species. This is valid since it is very unlikely that the presence or absence of ground-level shrubs affects tree choice by species flying to the canopies of pines. We categorized types 6-9 as "open" microhabitats and types $1-5$ as "covered" microhabitats. The relative abundance of these microhabitat types was estimated by random point sampling ( $N=700$ points) along 20, $120 \mathrm{~m}$ long parallel transects $(N=35$ random points/transect) running the length of the intensive study plot. Starting points of transects were randomly located along one short (90-m) side of the plot with a minimum separation of $2 \mathrm{~m}$ between adjacent transects.

To quantify microhabitat patterns of seedfall we sampled the five covered microhabitats with seed traps, $0.41 \times 0.41 \mathrm{~m}, 0.12 \mathrm{~m}$ depth plastic trays, covered with $1.2-\mathrm{cm}$ mesh wire to protect fallen seeds and fruits from potential consumption by animals. Previous trials showed that fallen fruits or seeds rarely bounce off the trap mesh (see Kollmann and Goetze 1997). For the four open microhabitats we used quadrats of the same size. The sampling scheme consisted of 15 replicates per microhabitat type, each with four traps or quadrats laid out in a square with $0.5-0.75 \mathrm{~m}$ between adjacent traps or quadrats. Traps and quadrats were in operation throughout the fruiting season (mid-July-mid-September, 1988 and 1989). Traps were checked weekly for identification and counts of fallen fruits and seeds. Quadrats were generally checked every day late in the afternoon following most seed dispersal but before rodent seed predators became active. On several occasions we skipped a day, but we have no reason to belive this should cause serious bias in the estimates. Locations of replicates for microhabitats $1-4$ were selected randomly from the total available shrubs or trees; those for category 5 were all those available within the plot. For open microhabitats (categories 6-9 above) we haphazardly selected three to four representative areas of each and pseudorandomly located three to five replicates in each area by blindly tossing a stick and setting the quadrats where it landed.

We characterized the environment surrounding each replicate (set of four traps or quadrats) by recording the following variables: (1) type of microhabitat (as described above); (2) distance from the center of the cluster of 4 traps or quadrats to the nearest edge of the nearest $P$. mahaleb $\geq 10.0 \mathrm{~cm}$ basal stem diameter (this size was chosen to represent a tree large enough to have a reasonably large fruit crop; i.e., exceeding 1000 fruits); (3) basal stem diameter of the nearest P. mahaleb; (4) distance to the nearest vegetation cover with thick tangle of stems or branches coming low to the ground ( $\leq 0.5 \mathrm{~m}$ above ground); (5) number of $P$. $\mathrm{ma}$ haleb trees $\geq 1 \mathrm{~m}$ tall with at least a portion of the crown within $10 \mathrm{~m}$ of the center of the four traps or quadrats; (6) basal stem diameters of these P. mahaleb trees with a portion of the crown within $10 \mathrm{~m}$ of the traps; and (7) number of $P$. mahaleb fruits on trees having at least one branch within $10 \mathrm{~m}$ of the traps or quadrats, estimated from the linear regression of fruit crop size against basal stem diameter (BSD, in centimeters; both variables log transformed) for a random sample of 90 trees in the study area: $\log$ (number of fruits $)=0.4546+2.1981 \log (\mathrm{BSD}) ; F=199.2$, df $\left.=2,84, P<0.0001, R^{2}=0.7059\right)$.

For each replicate and census date we tallied across all four traps or quadrats the number of intact ripe fruits that had not had any pulp consumed, the number with pieces of pulp attached (handled and dropped by PC species), the number of clean seeds (dispersed by SD species) and the number of seeds broken open, presumably by rodents in trees. Both clean seeds and seeds with pulp pieces attached or other signs of bird handling will be referred to as "removed fruits," while only clean seeds (regurgitated) or those in feces will 
TABLE 1. Fruiting intensity and estimated number and percentages of fruit removed and seed dispersed for Prunus mahaleb trees in two study years.

\begin{tabular}{|c|c|c|}
\hline Fruit and flower parameters & 1988 & 1989 \\
\hline Number of flowers $\dagger$ & $18048[1548-57768]$ & 15166 [1721-149000] \\
\hline Number of fruits $\dagger$ & 7565 [3275-9992] & $1935[1150-3707]$ \\
\hline Number of fruits removed $\dagger, \S$ & $4657[2228-7092]$ & $2396[1023-3433]$ \\
\hline$\%$ fruits removed $\$, \S$ & $74.97 \pm 2.45$ & $80.59 \pm 2.56$ \\
\hline Number of seeds dispersed from tree $\dagger, \mathscr{I}$ & $2664[1791-6237]$ & $1894[790-2850]$ \\
\hline$\%$ seeds dispersed $t, \mathbb{T}$ & $50.39 \pm 5.17$ & $67.82 \pm 3.71$ \\
\hline
\end{tabular}

$\dagger$ Median [25-75\% quantiles], $N=21$ trees.

$\$$ Mean \pm 1 SE $(N=21)$.

$\S$ Refers to overall fruit consumption and removal by legitimate (SD) and nonlegitimate (PC, PCSD, and SP) seed dispersers.

II Refers to fruit consumption and removal by legitimate (SD) seed dispersers only.

be referred to as "dispersed seeds" (see Jordano 1995 for details and definitions).

\section{Data analyses}

For statistical analyses we used parametric tests whenever their requirements were met. Original data were subjected to log- (for linear or mass measurements) or angular (percentages) transformations to normalize the data prior to parametric statistical tests. We used nonparametric tests or resampling statistics (Manly 1991) whenever transformations did not adequately normalize the data. In the case of very skewed distributions (e.g., crop sizes, seed rain data), we report the median and 25th-75th percentiles; the mean \pm 1 SE are given otherwise. Specifically, we used randomization tests for paired comparisons of fruit crop size data and number of seeds dispersed/tree in the two years. When randomization tests were applied to multiple regression analyses, we assessed the significance from the extra sum of squares accounted for by each $X_{j}$ variable when the others $X_{j-1}$ were already incorporated. We used Manly's (1991: 96-111) test, with additional routines from Press et al. (1992) and $N=5000$ resamplings.

We used survival analysis (LIFESTAT procedure; SAS Institute 1988) to test for differences in visitation patterns among trees, years, and frugivore groups (see Muenchow 1986). Advantages of failure-time methods to assess visitation patterns include comparing the shape of the distribution of failure times (time until a tree is visited by a bird), accounting adequately for censored data, and being robust to deviations from normality (Fox 1993). We tested the heterogeneity among groups (trees, years, etc.) by means of the Wilcoxon test (SAS Institute 1988) due to its increased power relative to the log-rank test when there is censoring. We recorded visit time to the nearest minute to minimize ties, which seriously reduce power (Muenchow 1986, Fox 1993).

\section{RESUlts}

\section{Fruiting and fruit removal}

Fruiting intensity and its correlates.-Flower production was similar in the two study years (Table 1; see Jordano $1993 b$ for details $)(P=0.502$, randomi- zation test for paired comparisons, $N=5000$ resamplings; Manly 1991). The number of full-sized fruits produced by individual plants was, however, significantly $(P=0.0001$, randomization test for paired comparisons) greater in 1988 than in 1989, with median fruit crops of 7565 fruits and 1935 fruits, respectively. As reported in Jordano (1993b), the sharp decrease in fruiting intensity during 1989 was due to extremely low pollination success associated with unfavorable weather conditions during the flowering period (e.g., only $18.0 \pm 2.4 \%$ flowers setting fruit in $1989, N=$ 39 inflorescences, compared to $46.9 \pm 3.8 \%, N=15$, in 1988). However, the rank order of fruit crop sizes remained relatively consistent, even with the marked between-year variation in fruiting intensity $\left(r_{\mathrm{s}}=0.457\right.$, $P=0.04, N=21$ )

Variation in individual fecundity could therefore be caused by a variety of factors, including individual size differences, intensity of flowering, and/or consistent variation in fruit set. Results of a multiple regression analysis for the 1988 and 1989 data revealed significant effects only for plant size $(1988, \beta=27.62, F=292.7$, df $=2,18, P=0.001, N=21$ trees; $1989, \beta=110.9$, $F=5.22$, df $=3,17, P=0.04$; randomization test, $N=5000$ resamplings; Manly 1991) and the initial number of flowers produced (only significant in 1988, $\beta=0.27, F=272.0$, df $=2,18, P=0.002, N=21$ trees) in determining fruit production.

Fruit removal and seed dispersal.-We compared fruit removal levels between years by means of repeated measures ANOVA, using repeated observations on the 21 marked trees. The overall number of fruits removed by avian frugivores differed only marginally between the two study years $(F=3.21$, df $=1,20, P$ $=0.09$ ) (Table 1). However, the estimated percentage of seeds dispersed (removed by legitimate dispersers) differed significantly, with lower relative dispersal success in $1988(F=19.52$, df $=1,20, P=0.0003)$ (Table 1). This difference reflects greater fruit losses to pulp and pulp-seed consumers in 1988 (24.58 \pm $3.62 \%)$ compared to $1989(12.77 \pm 3.61 \%)(F=5.31$, df $=1,20, P=0.02)$. This variation in the overall effect of frugivores on fruit removal did not result in between-year differences in seed dispersal: the absolute 
TABLE 2. Variance (increase in $R^{2}$ ) in two components of seed dispersal success.

\begin{tabular}{|c|c|c|c|c|}
\hline $\begin{array}{l}\text { Seed dispersal } \\
\text { component }\end{array}$ & $\begin{array}{l}\text { Fruit } \\
\text { crop size }\end{array}$ & $\begin{array}{l}\text { Percentage } \\
\text { fruits } \\
\text { desiccated }\end{array}$ & $\begin{array}{l}\text { Percentage fruits } \\
\text { consumed } \\
\text { by nonlegitimate } \\
\text { seed dispersers }\end{array}$ & $\begin{array}{c}\text { Fruit } \\
\text { diameter }\end{array}$ \\
\hline \multicolumn{5}{|l|}{1988} \\
\hline $\begin{array}{l}\text { Number of seeds } \\
\text { dispersed from tree } \\
\% \text { seeds dispersed }\end{array}$ & $\begin{array}{l}82.4^{* * * *} \\
0.7^{\mathrm{NS}}\end{array}$ & $\begin{array}{l}1.6^{\mathrm{NS}} \\
10.9^{*}\end{array}$ & $\begin{array}{l}13.1^{*} \\
83.0^{* * *}\end{array}$ & $\begin{array}{l}0.5^{\mathrm{NS}} \\
1.1^{\mathrm{NS}}\end{array}$ \\
\hline \multicolumn{5}{|l|}{1989} \\
\hline $\begin{array}{l}\text { Number of seeds } \\
\text { dispersed from tree } \\
\% \text { seeds dispersed }\end{array}$ & $\begin{array}{l}95.3^{* * *} \\
1.3^{\mathrm{NS}}\end{array}$ & $\begin{array}{l}1.2^{\mathrm{NS}} \\
36.5^{*}\end{array}$ & $\begin{array}{c}2.0^{\mathrm{NS}} \\
35.1^{* * *}\end{array}$ & $\begin{array}{l}0.8^{\mathrm{NS}} \\
4.2^{\mathrm{NS}}\end{array}$ \\
\hline
\end{tabular}

Notes: The components were the absolute number of seeds dispersed away from the canopy and the percentage, relative to initial fruit crop size, of Prunus mahaleb trees explained by number of fruits produced, fruit loss due to desiccation and consumption by nonlegitimate seed dispersers (PC, PCSD, and SP frugivores that eat fruit but do not disperse seeds), and fruit size. Values reported are the percentage variance in the two components of seed dispersal success explained by the four independent variables in a multiple-regression analysis, and its significance, estimated by randomization $(N=5000$ resamplings; Manly 1991:96).

$* P<0.05 ; * * * P \leq 0.001 ;$ NS $=$ not significant, $0.05<P<0.1$. Significance values are for the extra sums of squares accounted for by each variable with the remaining variables already in the model.

number of seeds dispersed per tree in 1988 (median $=$ 2664 seeds) was not significantly different from 1989 (1894 seeds) ( $P=0.40$; randomization test for paired comparisons, $N=5000$ resamplings), even with greater proportional removal success in this year.

Table 2 summarizes the results of a multiple regression analysis aimed at dissecting the correlates of seed dispersal success, estimated by its two components: the absolute number of seeds dispersed by legitimate dispersers (absolute dispersal success), and the proportion of seeds dispersed relative to the initial crop size (relative dispersal success). As expected, absolute dispersal success is primarily influenced by fruit crop size, which explains $>80 \%$ of the variation in both years. The partial $R^{2}$ accounted for by both losses due to desiccation (percentage fruits desiccated) and consumption by pulp/seed consumers (PC, PCSD, and SP frugivores, which are not legitimate seed dispersers) was small in both years. In contrast, relative dispersal success was greatly influenced by losses to nonlegitimate seed dispersers and desiccation, accounting together for $93.9 \%$ and $71.6 \%$ of the variation in 1988 and 1989, respectively (Table 2). For the two years pooled, the partial correlations between these two variables and relative dispersal success were $r=-0.976$ and -0.137 , respectively, suggesting a greater negative effect of consumption by pulp/seed consumers than of desiccation in determining relative removal success. The influence of fruit diameter on relative dispersal success was only marginally significant in both years (Table 2 ). To summarize, significantly higher relative dispersal success (Table 1) in the year with lower fruit production, largely caused by lower fruit consumption by nonlegitimate dispersers (Table 2), tended to compensate for the variation in fruit crop sizes yielding similar absolute numbers of seeds dispersed from trees (Table 1).

\section{The quantity component of seed dispersal and its correlates}

Bird abundance.-A total of 38 species of birds were recorded during censuses, with frugivores representing $68.8 \%$ of them. SD species accounted for $42.2 \%$, PC species for $17.2 \%$, and PCSD species for $9.4 \%$ of all the species recorded (Table 3). Between-year differences in the proportions of species in these frugivory groups were not significant $\left(\chi^{2}=0.56\right.$, df $=2, P=$ 0.90 ). The overall frugivore abundance (averaged over censuses) also did not differ significantly between the two study years $(128 \pm 33$ birds $/ \mathrm{km}, N=6$ censuses in $1988 ; 105 \pm 13 \mathrm{birds} / \mathrm{km}, N=8$ censuses in 1989 ; $F=0.11$, df $=1,48, P=0.73$ ). We explored trends in between-year changes in community and functional group abundances by means of paired comparisons of both the absolute abundances of frugivore species (Table 3 ) and the proportion of total individuals recorded that year that were contributed by each species. There was no consistent trend for either increase or decrease in the abundances of individual frugivore species (signed-ranks test $=-35.5, P=0.35$ ). However, considered as a group, there was a significant increase from 1988 to 1989 in both the number (signed-ranks test $=$ 65.0, $P<0.0001$ ) and proportion (signed-ranks test $=$ $65.0, P<0.0001)$ of SD individuals, as well as a marginally significant decrease of proportion of $\mathrm{PC}$ (signed-ranks test $=9.5, P=0.06$ ), with no evident trend for either numbers or proportions of PCSD (signed-ranks tests $<-3.0, P=0.25$ ). Erithacus rubecula and Turdus viscivorus were important SD species showing greater abundance in 1989, while the main PC species, Fringilla coelebs, showed a dramatic decrease in that year (Table 3). To summarize, there were no significant trends in overall frugivore abundance 
TABLE 3. Relative abundances and feeding records of frugivorous birds visiting Prunus mahaleb trees in the two study years.

\begin{tabular}{|c|c|c|c|c|c|}
\hline \multirow[b]{2}{*}{ Species } & \multirow{2}{*}{$\begin{array}{c}\text { Frugivory } \\
\text { type } \dagger\end{array}$} & \multicolumn{2}{|c|}{1988} & \multicolumn{2}{|c|}{1989} \\
\hline & & Abundance $\neq$ & Records $§$ & Abundance $\neq$ & Records $\S$ \\
\hline Columba palumbus & SD & $0.2 \pm 0.2(0.2)$ & $2(0.1)$ & $0.7 \pm 0.5(0.6)$ & $5(0.6)$ \\
\hline Corvus corone & SD & 0 & 0 & $1.3 \pm 0.5(1.2)$ & $3(0.3)$ \\
\hline Dendrocopos major & SD & 0 & $4(0.2)$ & $4.0 \pm 0.3(0.2)$ & 0 \\
\hline Erithacus rubecula & SD & $5.5 \pm 1.2(4.3)$ & $140(7.2)$ & $6.6 \pm 0.9(5.9)$ & $64(7.0)$ \\
\hline Ficedula hypoleuca & SD & $0.2 \pm 0.2(0.2)$ & 0 & $0.2 \pm 0.2(0.1)$ & 0 \\
\hline Muscicapa striata & SD & 0 & 0 & $0.2 \pm 0.2(0.1)$ & 0 \\
\hline Phoenicurus ochruros & SD & $24.3 \pm 7.2(19.3)$ & $417(21.5)$ & $21.3 \pm 2 \quad(19.9)$ & $192(21.0)$ \\
\hline Phoenicurus phoenicurus & SD & $1.7 \pm 0.9(1.2)$ & $18(0.9)$ & $5.3 \pm 0.6(4.9)$ & $52(5.7)$ \\
\hline Sylvia atricapilla & SD & $2.0 \pm 0.7(1.6)$ & $19(1.0)$ & $1.2 \pm 0.5(1.3)$ & $15(1.6)$ \\
\hline Sylvia borin & SD & 0 & $6(0.3)$ & $0.4 \pm 0.2(0.3)$ & $3(0.3)$ \\
\hline Sylvia cantillans & SD & $1.2 \pm 0.5(0.9)$ & $27(1.4)$ & $0.6 \pm 0.3(0.6)$ & $33(3.6)$ \\
\hline Sylvia communis & SD & $7.0 \pm 1.8(5.5)$ & $85(4.4)$ & $8.4 \pm 1.6(8.0)$ & $65(7.1)$ \\
\hline Sylvia conspicillata & SD & $0.2 \pm 0.2(0.2)$ & $2(0.1)$ & 0 & 0 \\
\hline Sylvia melanocephala & SD & $1.1 \pm 0.4(0.9)$ & $8(0.4)$ & $1.4 \pm 0.5(1.2)$ & $9(1.0)$ \\
\hline Turdus merula & SD & $11.2 \pm 3$ & $150(7.7)$ & $9.0 \pm 1.6(8.2)$ & $79(8.7)$ \\
\hline Turdus viscivorus & SD & $10.4 \pm 3$ & $380(19.6)$ & $14.6 \pm 5.3(13.8)$ & $105(11.5)$ \\
\hline Garrulus glandarius & PCSD & $0.8 \pm 0.7(0.5)$ & $31(1.6)$ & $3.6 \pm 0.8(3.4)$ & $37(4.1)$ \\
\hline Parus ater & PCSD & $6.5 \pm 1.1(4.6)$ & $119(6.1)$ & $5.2 \pm 0.9(6.2)$ & $94(10.3)$ \\
\hline Sitta europaea & PCSD & $1.1 \pm 0.6(0.7)$ & $14(0.7)$ & $1.4 \pm 0.4(1.2)$ & $14(1.5)$ \\
\hline Fringilla coelebs & $\mathrm{PC}$ & $37.8 \pm 9.7(30.2)$ & $477(24.6)$ & $10.9 \pm 2.8(11.0)$ & $71(7.8)$ \\
\hline Parus caeruleus & $\mathrm{PC}$ & $1.1 \pm 0.6(0.9)$ & $27(1.4)$ & $2.0 \pm 0.4(1.8)$ & $60(6.6)$ \\
\hline Parus cristatus & $\mathrm{PC}$ & $0.6 \pm 0.4(0.5)$ & $11(0.6)$ & $0.5 \pm 0.3(0.5)$ & $4(0.4)$ \\
\hline Parus major & $\mathrm{PC}$ & $0.9 \pm 0.6(0.7)$ & $4(0.2)$ & $0.5 \pm 0.3(0.5)$ & $6(0.7)$ \\
\hline Serinus citrinella & $\mathrm{PC}$ & $0.5 \pm 0.5(0.4)$ & 0 & $0.3 \pm 0.3(0.3)$ & $1(0.1)$ \\
\hline Serinus serinus & $\mathrm{PC}$ & 0 & 0 & $0.2 \pm 0.2(0.1)$ & $1(0.1)$ \\
\hline
\end{tabular}

$\dagger$ SD, seed disperser; PC, pulp consumer; PCSD, pulp consumer-seed disperser.

\$ Number of birds censused/km; mean $\pm 1 \mathrm{SE}$, and percentage of total birds censused (in parentheses).

$\S$ Number of feeding records, and percentage of the annual total for all species combined (in parentheses).

between the two study years; 10 of 16 SD species tended to increase in abundance in 1989, and 4 out of 6 PC species tended to decrease, resulting in a greater relative and absolute representation of $\mathrm{SD}$ species among frugivores in 1989, the year with greater relative seed dispersal success.

Visitation.-Individual trees showed extensive variation in visitation rates (Fig. 1), ranging from 0.3 to 41.6 visits/10 h (in either year). Between-tree differences in visitation, as depicted by the survivorship functions for both 1988 and 1989 (Fig. 1), were highly significant $\left(\chi^{2}=94.8, P<0.0001\right.$ and $\chi^{2}=234.2, P$ $<0.0001$, respectively; Wilcoxon test, SAS Institute 1988). Only four trees $(1931,1932,1933$, and 1939 , Fig. 1) differed in visitation rate between years $\left(\chi^{2}>\right.$ $4.5, P<0.03)$. For the remaining trees, both the composition of the assemblage and visitation rates were similar in the two years. Though not significantly, overall visitation rate tended to decrease for most trees in 1989.

Birds favored similar trees in both years (tree numbers 1820, 1823, 1921, 1937-1940; Fig. 1), while other trees $(1929,1934,1936)$ consistently received few visits (Fig. 1). Visitation by the four types of frugivores differed significantly among individual trees $\left(\chi^{2}=\right.$ $166.9, P \ll 0.0001)$, but not between years $\left(\chi^{2}=0.11\right.$, $P=0.94)$, although the tree $\times$ year interaction was significant $\left(\chi^{2}=52.41, P<0.01\right)$ (model with tree and year as main effects; CATMOD procedure, SAS Institute 1988).

Individual bird species differed significantly in visit rate measured as the number of visits per $10 \mathrm{~h}(F=$ 5.91, df $=1,18, P<0.0001)$, with no significant species $\times$ year interaction $(F=0.69$, df $=1,18, P=$ $0.83)$. Frequent visitors to the trees included both SD (P. ochruros, 10.8 visits/10 h; T. viscivorus, 9.2 visits/ $10 \mathrm{~h} ;$ E. rubecula, 3.5 visits $/ 10 \mathrm{~h}$; and $S$. communis, 2.6 visits $/ 10 \mathrm{~h}$ ) and PC or PCSD species ( $F$. coelebs, 16.7 visits $/ 10 \mathrm{~h} ; P$. ater, 4.7 visits $/ 10 \mathrm{~h}$ ).

Feeding behavior.-Avian frugivores visiting $P$. mahale $b$ trees showed three types of feeding behavior with regard to the proximate consequences for the plant (Table 4). Legitimate seed dispersers (SD) swallow fruits whole, usually $>75 \%$ of the fruits handled (they never pecked the fruits for pulp pieces), and defecate or regurgitate the seeds unharmed. Once a fruit is detached, failures to swallow handled fruits are largely a consequence of small body size and gape width. The smaller species typically fail to successfully detach fruits from peduncles, or drop detached fruits due to handling failures (Table 4). Thus, among Sylvia species, the percentage of fruits swallowed decreased with decreasing gape width from the larger $S$. borin $(100.0 \%$ fruits swallowed) to $S$. communis $(95.2 \%)$ and $S$. atricapilla $(95.0 \%)$ to $S$. melanocephala $(83.3 \%)$ to $S$. cantillans $(72.8 \%)$, to $S$. conspicillata $(18.2 \%)$. These differences 


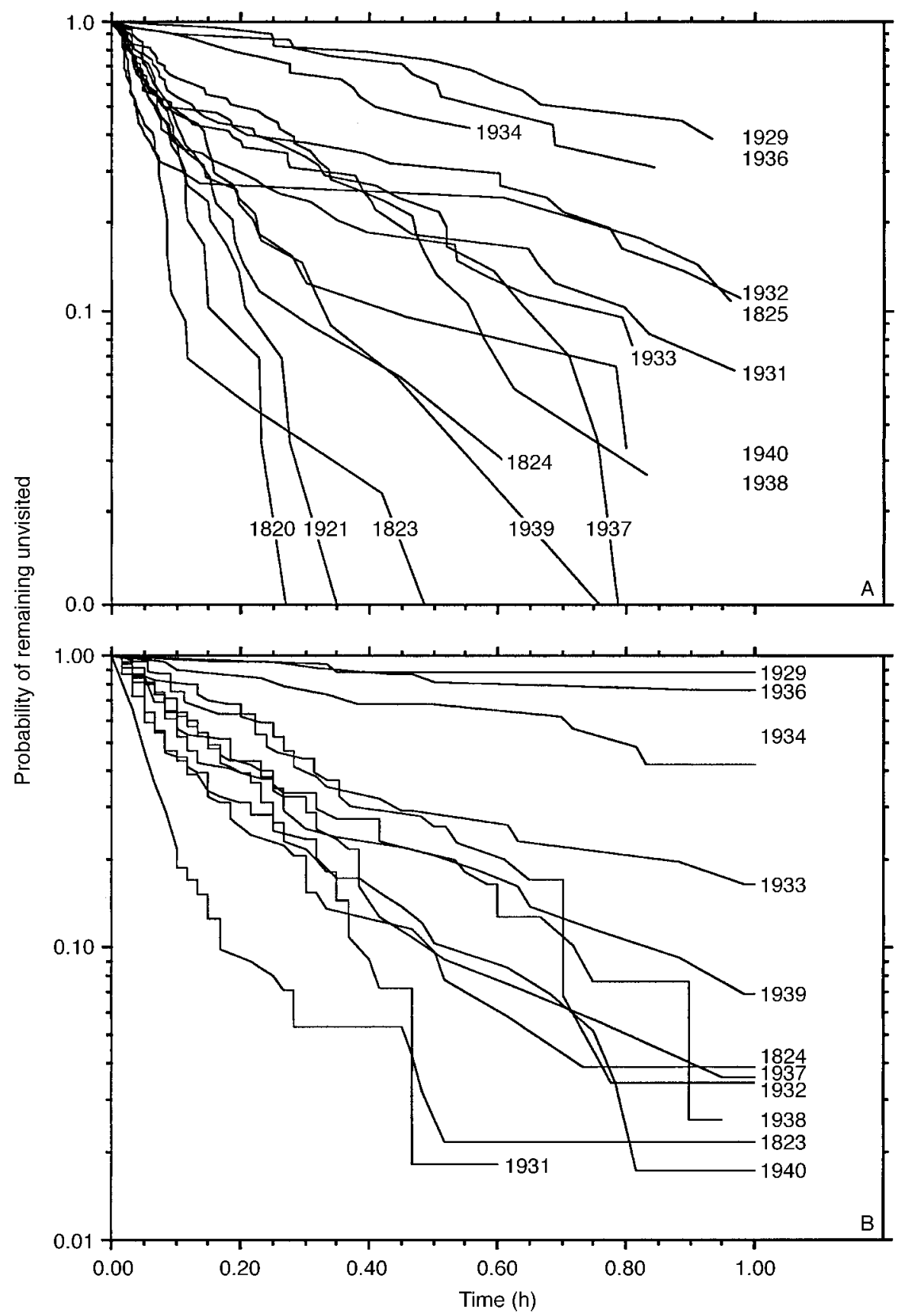

FIG. 1. Product-limit estimates of the survivorship functions describing visitation by frugivorous birds to individual Prunus mahaleb trees in (A) 1988 and (B) 1989. Individual trees are numbered. The curves depict, for each tree, the decreasing probability that a tree will remain unvisited (steeper curves illustrate trees with more visitation). Note logarithmic ordinate scales. Plotted on the abcissa is the time elapsed since the start of an observation period.

among Sylvia species in percent fruits swallowed were significant $(F=2.70$, df $=3,46, P=0.048)$. In contrast, congeneric species spanning smaller size differences did not differ in percentage of fruits swallowed ( $F=2.63$, df $=1,55, P=0.10$, Phoenicurus spp.; $F$ $=2.33$, df $=1,69, P=0.13$, Turdus spp.; Table 4). The percentage of fruits swallowed was positively cor- related with gape width across all SD species $\left(r_{\mathrm{s}}=\right.$ 0.723, $P=0.03, N=10$; gape width measurements from P. Jordano, unpublished data).

Pulp consumers (PC) do not swallow any fruit. Rather, they peck fruits and separate pieces of pulp, either from fruits not detached from the infructescences ("Pecked," Table 4) or from fruits that have been 
plucked and are handled in the bill or against a branch ("Picked," Table 4). All the seeds picked by PC species are dropped beneath the parent plant, and the pecked fruits almost always end up there as well (Table 4). Pulp consumers-seed dispersers (PCSD) are PC species that occasionally swallow fruits whole ( $G$. glandarius, $S$. europaea), leave the tree to cache fruits in crevices of nearby branches ( $S$. europaea, $P$. ater), or go to another tree to eat the pulp ( $P$. ater). Thus, all of these species occasionally perform dispersal (Table 5). All the parids, S. europaea, and G. glandarius usually picked fruits, held them against the perch, and pulled off tiny pieces of pulp. In contrast, $F$. coelebs and other finches frequently pecked the fruits, leaving the seeds with variable amounts of pulp attached to the peduncles. Despite the occasional dispersal event, the percentage of removed seeds that is actually dispersed away from the parent plant by these species was generally very low (Table 4 ).

Feeding rates varied widely among frugivore species (Table 5, Fig. 2), ranging from 0.4 to 7.4 fruits/min. The number of seeds potentially dispersed per visit varied even more, as a consequence of differences in visit duration, feeding rate, and percentage of fruits swallowed (Tables 4 and 5). The larger species ( $C$. palumbus, D. major, G. glandarius, and Turdus spp.) took $>5$ seeds/visit on average, due to larger body size, while smaller species took only $\sim 3$ fruits/visit on average (Table 5). Both the number of seeds removed per visit ( $r=0.922, P<0.01, N=24)$ and the number dispersed away from the tree $(r=0.763, P<0.01)$ were positively correlated across species with body size (both body mass and gape width). Relative to both PC and PCSD species, SD species dropped significantly smaller percentages of seeds per visit (Table 4), moved less frequently but spent less time stopped per fruit handled (see Fig. 2), removed more fruits per minute of foraging, and swallowed and dispersed a greater number of seeds per visit (Tables 4 and 5) $(P<0.0001$ for all a posteriori, Scheffé contrasts among frugivory types).

Visits were typically of short duration, $<2 \mathrm{~min}(\mathrm{Ta}-$ ble 5), with feeding sequences (Fig. 2) including bouts of movement, while looking for fruits within the canopy, alternating with pauses that include resting and/ or fruit-handling time. Frugivores in the SD, PCSD, and PC categories differed markedly in the shape and patterns of these foraging curves, illustrating contrasting patterns of fruit foraging. Most SD species (Sylvia spp., C. palumbus, Turdus spp., Fig. 2) foraged by gleaning fruits from perches, using rapid movements and very short handling times. Characteristic foraging curves for these species (Fig. 2) include a steep "ladder" with narrow steps. The number of fruits handled per minute by gleaners (from 3.8 in $S$. communis to 8.2 in $T$. merula) was well above the feeding rate of other SD species that forage for fruits either by hopping from branch to branch or on the wing (E. rubecula, 2.5 fruits/min, and Phoenicurus spp., 3.1 fruits/min). The foraging bouts of these species showed less frequent moves (more time stopped between fruit handlings), but handling times were similar, as they also swallow fruits whole. Their characteristic foraging curve (Fig. 2 ) is not steep, with wide steps reflecting the longer stop periods among feeding bouts. The foraging curves for both PCSD and PC species (G. glandarius, S. europaea, $P$. ater, and $F$. coelebs) differed markedly from these patterns. They are low-slope "ladders" with narrow but high steps, reflecting the greater handling time per fruit. In contrast, foraging moves among fruit "captures" were extremely short, as illustrated by $P$. ater (Fig. 2).

Correlates of the quantity component of seed dispersal.-Table 6 summarizes variables that determine the quantity component of disperser effectiveness for each of the main frugivore species in $P$. mahaleb seed dispersal. Species differed widely in all variables (Table 6). There was a significant trend for SD species to score with larger quantity components (Kruskal-Wallis test; $\chi^{2}=7.97$, df $\left.=2, P=0.019\right)$. Those with large quantity component values (T. viscivorus, $T$. merula, $P h$. ochruros, E. rubecula, and $S$. communis) typically showed high visit and/or high feeding rates, combined with a high probability of seed dispersal. F. coelebs, however, had a relatively high quantity component despite a low probability of dispersing removed seeds because it had an extremely high visit rate (Table 6).

To account for the relative influences of abundance, visit rate, fruits per visit, and probability of dispersing handled seeds (Table 6) on the quantity component, we examined the standardized coefficients for the regression of log-transformed values of the quantity component on the log-transformed values of these variables. The model accounted for $82.2 \%$ of the variation in the quantity component across species $(F=21.97$, df $=4,19, P<0.0001)$, but only visit rate $(t=3.01$, $P=0.007)$, fruits per visit $(t=2.67, P=0.015)$, and probability of dispersing handled seeds $(t=4.22, P=$ $0.0005)$ had significant effects. The high partial correlation between abundance and visit rate $\left(r_{\text {part }}=\right.$ 0.7388 ) indicates a significant, but indirect, effect of abundance on the quantity component mediated by its influence on visit rate. Taken together, fruit handling variables seem to have a greater effect on the quantity component than visit rate or abundance in the area, especially if comparing SD vs. PC species (with zero or very low probability of dispersing a handled seed). For example, species with relatively infrequent visits and low abundance in the area (S. atricapilla and $P h$. phoenicurus) but with high probability of dispersing handled seeds show higher quantity component values than species that disperse few seeds but visit trees frequently ( $P$. ater, F. coelebs; Table 6).

\section{Among-tree variation in visitation and seed dispersal success}

The number of seeds dispersed from trees by each bird species is the product of its visit rate and the num- 
TAble 4. Fate of fruits and seeds consumed by frugivorous birds visiting Prunus mahaleb trees (data from 1988 and 1989 combined).

\begin{tabular}{|c|c|c|c|c|c|}
\hline \multirow[b]{2}{*}{ Species } & \multirow[b]{2}{*}{$N$} & \multicolumn{4}{|c|}{ Fruit and seed handling $\dagger$} \\
\hline & & Swallowed & Carried & Failed & Dropped \\
\hline Columba palumbus & 7 & 100.0 & 0.0 & 0.0 & 0.0 \\
\hline Dendrocopos major & 4 & $95.8 \pm 4.2$ & 0.0 & $4.2 \pm 4.2$ & 0.0 \\
\hline Erithacus rubecula & 13 & 100.0 & 0.0 & 0.0 & 0.0 \\
\hline Fringilla coelebs & 51 & 0.0 & $0.4 \pm 0.4$ & 0.0 & 0.0 \\
\hline Garrulus glandarius & 32 & $6.8 \pm 4.2$ & $7.0 \pm 4.4$ & $0.3 \pm 0.3$ & $0.3 \pm 0.3$ \\
\hline Parus ater & 18 & 0.0 & $14.4 \pm 7.7$ & $8.3 \pm 6.1$ & 0.0 \\
\hline Parus caeruleus & 12 & 0.0 & 0.0 & 0.0 & 0.0 \\
\hline Parus major & 5 & 0.0 & 0.0 & 0.0 & 0.0 \\
\hline Phoenicurus ochruros & 45 & $88.9 \pm 3.7$ & 0.0 & $15.6 \pm 4.3$ & $6.7 \pm 2.7$ \\
\hline Phoenicurus phoenicurus & 12 & $97.2 \pm 2.8$ & 0.0 & $5.6 \pm 3.7$ & $2.8 \pm 2.8$ \\
\hline Sitta europaea & 6 & $4.2 \pm 4.2$ & $55.6 \pm 20.5$ & 0.0 & 0.0 \\
\hline Sylvia cantillans & 9 & $72.8 \pm 11.0$ & 0.0 & $27.2 \pm 11.0$ & $27.2 \pm 11.0$ \\
\hline Sylvia communis & 36 & $84.8 \pm 3.8$ & 0.0 & $15.2 \pm 3.8$ & $15.2 \pm 3.8$ \\
\hline Sylvia melanocephala & 3 & $83.3 \pm 16.7$ & 0.0 & $16.7 \pm 16.7$ & $16.7 \pm 16.7$ \\
\hline Turdus merula & 15 & $92.9 \pm 3.8$ & $3.3 \pm 3.3$ & $5.5 \pm 2.3$ & $1.9 \pm 1.3$ \\
\hline Turdus viscivorus & 56 & $99.9 \pm 0.1$ & 0.0 & $0.1 \pm 0.1$ & $0.1 \pm 0.1$ \\
\hline
\end{tabular}

Note: Entries are percentages, mean $\pm 1 \mathrm{SE}$, of the fruits "touched" during visits.

$\dagger$ Percentages of fruits swallowed, carried away from the tree in the bill, failed to detach from peduncles, and dropped.

$\$$ Method of fruit handling by nonlegitimate seed dispersers (legitimate dispersers pluck all fruits): pecking is defined as biting pulp pieces without detaching the fruits from peduncles; picking is defined as plucking fruits and dropping them after tearing off pulp pieces.

$\S$ Percentages of seeds estimated to leave the tree after feeding bouts, or that fall beneath the tree.

ber of seeds successfully dispersed per visit. Given that individual trees differed widely in the identity and visit rate of different bird species, we might expect amongtree differences in seed removal to reflect this variation. Thus, the percentage of total visits by SD species to individual trees ranged from $18.75 \%$ to $92.31 \%$ in 1988 and $23.68 \%$ to $100.0 \%$ in 1989 , with a marginal trend for the percentage of visits by SD species to be correlated between years for individual trees $\left(r_{\mathrm{s}}=0.449\right.$, $P=0.08, N=16$ trees).

Data for both bird visitation and seed dispersal success is available for only 11 trees. To assess the relative effects of visitation by the three frugivore groups, we fit a regression model including the percentage of seeds dispersed as a dependent variable (estimating relative seed dispersal success) and the percentage of visits by SD, PCSD, and PC species for the two years pooled. Among-tree variation in the proportion of visits made by the three frugivore groups accounted for a significant fraction of variance in relative seed dispersal success $\left(F=6.70, \mathrm{df}=3,17, P=0.003, R^{2}=0.542\right)$. Seed dispersal success was positively significantly correlated with visitation by SD species (standardized regression coefficient, $b=0.882, t=4.48, P=0.0003$ ), and negatively significantly correlated with visitation by PC species $(b=-0.599, t=2.55, P=0.021)$.

TABle 5. Fruit-removal and seed-dispersal statistics for avian frugivores visiting Prunus mahaleb trees.

\begin{tabular}{|c|c|c|c|c|c|c|}
\hline \multirow[b]{2}{*}{ Species } & \multirow[b]{2}{*}{$N$} & \multirow{2}{*}{$\begin{array}{c}\text { Visit } \\
\text { duration (min) }\end{array}$} & \multirow{2}{*}{$\begin{array}{l}\text { No. fruits } \\
\text { per visit }\end{array}$} & \multirow{2}{*}{$\begin{array}{l}\text { No. seeds } \\
\text { per visit }\end{array}$} & \multicolumn{2}{|c|}{ No. seeds removed } \\
\hline & & & & & Away & Beneath \\
\hline Columba palumbus & 7 & $4.4 \pm 0.6$ & $22.4 \pm 3.8$ & $22.4 \pm 3.8$ & $22.4 \pm 3.8$ & 0.0 \\
\hline Dendrocopos major & 4 & $1.2 \pm 0.1$ & $5.0 \pm 0.7$ & $4.5 \pm 0.4$ & $4.5 \pm 0.4$ & 0.0 \\
\hline Erithacus rubecula & 13 & $0.8 \pm 0.1$ & $1.9 \pm 0.2$ & $1.9 \pm 0.2$ & $1.9 \pm 0.2$ & 0.0 \\
\hline Fringilla coelebs & 51 & $1.5 \pm 0.1$ & $3.4 \pm 0.2$ & $3.4 \pm 0.2$ & $0.0 \pm 0.0$ & $3.4 \pm 0.2$ \\
\hline Garrulus glandarius & 32 & $1.9 \pm 0.2$ & $6.9 \pm 0.8$ & $6.9 \pm 0.8$ & $1.1 \pm 0.5$ & $5.7 \pm 0.8$ \\
\hline Parus ater & 18 & $0.8 \pm 0.1$ & $1.9 \pm 0.2$ & $1.9 \pm 0.2$ & $0.2 \pm 0.1$ & $1.6 \pm 0.2$ \\
\hline Parus caeruleus & 12 & $1.0 \pm 0.3$ & $2.1 \pm 0.3$ & $2.1 \pm 0.3$ & 0.0 & $2.1 \pm 0.3$ \\
\hline Parus major & 5 & $0.9 \pm 0.2$ & $2.0 \pm 0.4$ & $2.0 \pm 0.4$ & 0.0 & $2.0 \pm 0.4$ \\
\hline Phoenicurus ochruros & 45 & $0.7 \pm 0.1$ & $1.8 \pm 0.2$ & $1.7 \pm 0.2$ & $1.5 \pm 0.1$ & $0.2 \pm 0.1$ \\
\hline Phoenicurus phoenicurus & 12 & $0.8 \pm 0.1$ & $2.4 \pm 0.2$ & $2.4 \pm 0.2$ & $2.3 \pm 0.2$ & $0.1 \pm 0.1$ \\
\hline Sitta europaea & 6 & $1.1 \pm 0.3$ & $2.5 \pm 0.6$ & $2.5 \pm 0.6$ & $1.0 \pm 0.3$ & $1.5 \pm 0.7$ \\
\hline Sylvia cantillans & 9 & $0.8 \pm 0.2$ & $2.9 \pm 0.9$ & $2.9 \pm 0.9$ & $1.6 \pm 0.4$ & $1.2 \pm 0.6$ \\
\hline Sylvia communis & 36 & $0.7 \pm 0.1$ & $2.8 \pm 0.2$ & $2.8 \pm 0.2$ & $2.2 \pm 0.2$ & $0.5 \pm 0.1$ \\
\hline Sylvia melanocephala & 3 & $0.6 \pm 0.1$ & $1.5 \pm 0.4$ & $1.5 \pm 0.4$ & $1.0 \pm 0.0$ & $0.5 \pm 0.4$ \\
\hline Turdus merula & 15 & $0.9 \pm 0.1$ & $6.5 \pm 0.7$ & $6.3 \pm 0.7$ & $6.1 \pm 0.7$ & $0.2 \pm 0.1$ \\
\hline Turdus viscivorus & 56 & $1.4 \pm 0.1$ & $9.7 \pm 0.5$ & $9.7 \pm 0.5$ & $9.7 \pm 0.5$ & 0.0 \\
\hline
\end{tabular}

Values are means \pm 1 SE. $N=$ number of feeding observations; only for species with at least three observations. 
TABle 4. Extended.

\begin{tabular}{|c|c|c|c|}
\hline \multicolumn{2}{|c|}{ Fruit picking } & \multicolumn{2}{|c|}{ Seed delivery§ } \\
\hline Pecked & Picked & Away & Beneath \\
\hline 0.0 & 0.0 & 100.0 & 0.0 \\
\hline 0.0 & 0.0 & $95.8 \pm 4.2$ & 0.0 \\
\hline 0.0 & 0.0 & 100.0 & 0.0 \\
\hline $45.5 \pm 6.3$ & $53.7 \pm 6.2$ & $0.4 \pm 0.4$ & $99.2 \pm 0.8$ \\
\hline 0.0 & $85.9 \pm 5.9$ & $13.9 \pm 5.8$ & $86.1 \pm 5.8$ \\
\hline $9.4 \pm 6.1$ & $76.2 \pm 8.9$ & $14.4 \pm 7.7$ & $85.6 \pm 7.7$ \\
\hline $16.7 \pm 11.2$ & $83.3 \pm 11.2$ & 0.0 & 100.0 \\
\hline 0.0 & 100.0 & 0.0 & 100.0 \\
\hline 0.0 & 0.0 & $88.9 \pm 3.7$ & $6.7 \pm 2.7$ \\
\hline 0.0 & 0.0 & $97.2 \pm 2.8$ & $2.8 \pm 2.8$ \\
\hline 0.0 & $40.3 \pm 18.6$ & $59.7 \pm 18.6$ & $40.3 \pm 18.6$ \\
\hline 0.0 & 0.0 & $72.8 \pm 11.0$ & $27.2 \pm 11.0$ \\
\hline 0.0 & 0.0 & $84.8 \pm 3.8$ & $15.2 \pm 3.8$ \\
\hline 0.0 & 0.0 & $83.3 \pm 16.7$ & $16.7 \pm 16.7$ \\
\hline 0.0 & 0.0 & $96.2 \pm 2.2$ & $1.9 \pm 1.3$ \\
\hline 0.0 & 0.0 & $99.9 \pm 0.1$ & $0.1 \pm 0.1$ \\
\hline
\end{tabular}

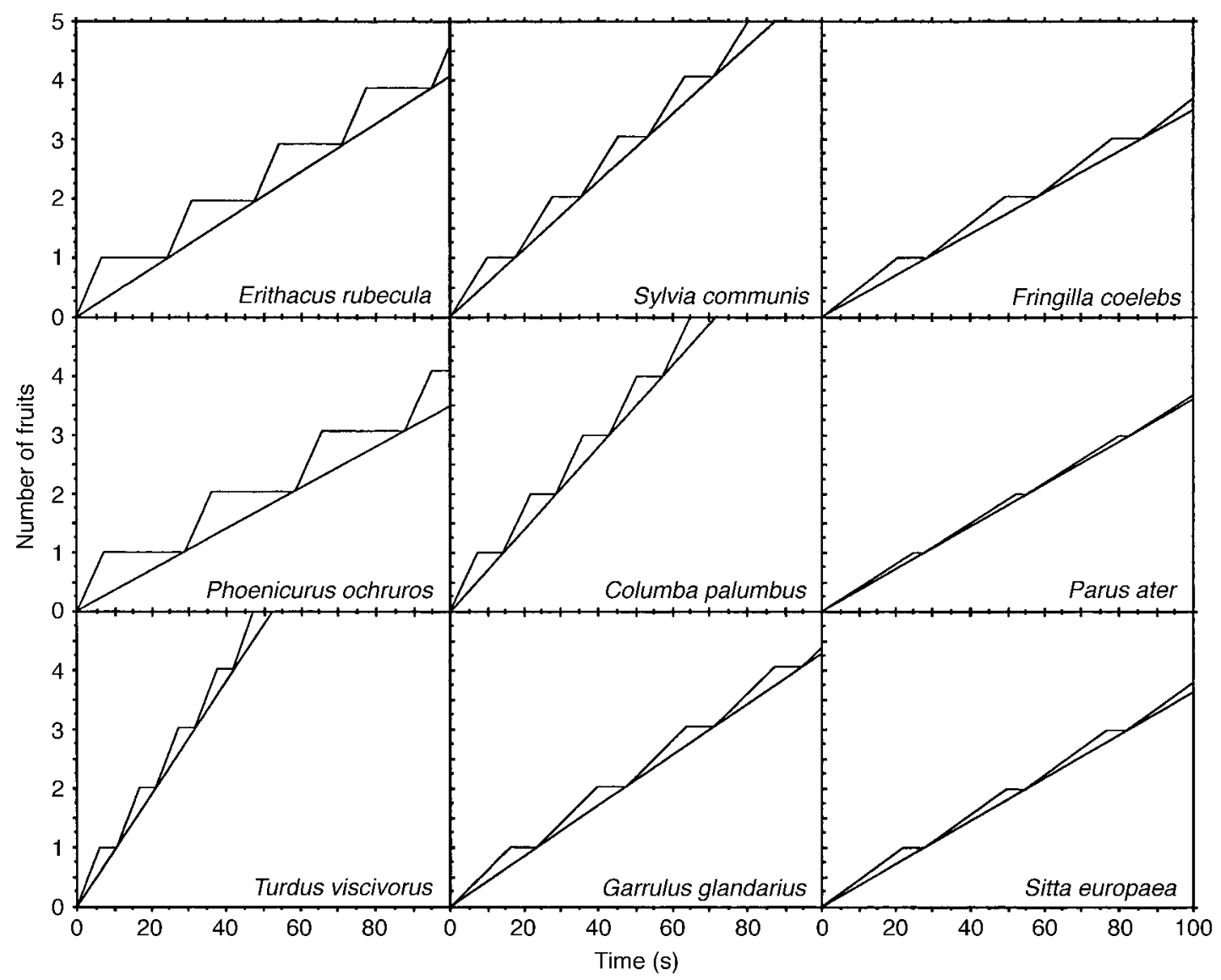

FIG. 2. Feeding rates of main bird species visiting Prunus mahaleb trees. Foraging rates are illustrated as sawtooth curves for each species-specific feeding behavior. The usual feeding sequence includes a series of short bouts separating successive ingestion of fruits. The horizontal projection of each bout (tooth) is the total time invested per fruit. The horizontal part of the step depicts the time stopped after each fruit ingestion; the ascending portion of the step depicts the time involved in searching for and/or handling the fruit. The average feeding rate (in fruits ingested per unit time) is depicted by the slope of the straight line. See Cody (1974:39-41) for further description of this type of graph. 
TABle 6. Summary of main variables associated with the quantity component of Prunus mahaleb seed dispersal by frugivorous birds.

\begin{tabular}{|c|c|c|c|c|c|c|c|}
\hline Species & $\begin{array}{c}\text { Frugivory } \\
\text { type }\end{array}$ & Abundance $\dagger$ & Diet: & $\begin{array}{l}\text { Visit } \\
\text { rate§ }\end{array}$ & $\begin{array}{l}\text { No. fruits } \\
\text { handled } \\
\text { per visit }\end{array}$ & $\begin{array}{l}\text { Probability of } \\
\text { dispersing a } \\
\text { handled seed }\end{array}$ & $\begin{array}{l}\text { Quantity } \\
\text { component }\end{array}$ \\
\hline Columba palumbus & SD & 0.45 & - & 0.01 & 22.4 & 1.000 & 0.20 \\
\hline Dendrocopos major & SD & 2.00 & • & 0.25 & 5.0 & 1.000 & 1.12 \\
\hline Erithacus rubecula & SD & 6.05 & ...• & 3.50 & 1.9 & 1.000 & 6.99 \\
\hline Ficedula hypoleuca & SD & 0.20 & • & + & 1.0 & 1.000 & 0.05 \\
\hline Muscicapa striata & SD & 0.10 & - & + & 1.0 & 1.000 & 0.05 \\
\hline Phoenicurus ochruros & SD & 22.80 & ...• & 10.85 & 1.8 & 0.872 & 17.45 \\
\hline Phoenicurus phoenicurus & SD & 3.50 & 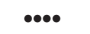 & 1.47 & 2.4 & 0.964 & 3.31 \\
\hline Sylvia atricapilla & SD & 1.60 & 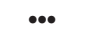 & 0.64 & & 0.950 & 1.70 \\
\hline Sylvia borin & SD & 0.20 & •• & 0.11 & 4.0 & 1.000 & 0.45 \\
\hline Sylvia cantillans & SD & 0.90 & $\bullet$ & 0.61 & 2.9 & 0.536 & 1.01 \\
\hline Sylvia communis & SD & 7.70 & œ.• & 2.63 & 2.8 & 0.814 & 6.06 \\
\hline Sylvia conspicillata & SD & 0.10 & $\bullet$ & + & $\ldots$ & 0.182 & 0.03 \\
\hline Sylvia melanocephala & $\mathrm{SD}$ & 1.25 & •• & + & 1.5 & 0.750 & 0.05 \\
\hline Turdus merula & SD & 10.10 & .•• & 2.82 & 6.5 & 0.979 & 17.65 \\
\hline Turdus viscivorus & $\mathrm{SD}$ & 12.50 & ••• & 9.23 & 9.7 & 0.998 & 83.19 \\
\hline Garrulus glandarius & PCSD & 2.20 & •• & 1.76 & 6.9 & 0.139 & 1.32 \\
\hline Parus ater & PCSD & 5.85 & .. & 4.67 & 1.9 & 0.111 & 1.04 \\
\hline Sitta europaea & PCSD & 1.25 & • & 0.48 & 2.5 & 0.400 & 0.48 \\
\hline Fringilla coelebs & $\mathrm{PC}$ & 24.30 & .• & 16.72 & 3.4 & 0.060 & 3.30 \\
\hline Parus caeruleus & $\mathrm{PC}$ & 1.55 & - & 2.51 & 2.1 & 0.000 & 0.00 \\
\hline Parus cristatus & $\mathrm{PC}$ & 0.55 & - & 0.24 & 2.0 & 0.000 & 0.00 \\
\hline Parus major & $\mathrm{PC}$ & 0.70 & - & 0.65 & 2.0 & 0.000 & 0.00 \\
\hline Serinus citrinella & $\mathrm{PC}$ & 0.40 & • & + & 6.5 & 0.000 & 0.00 \\
\hline Serinus serinus & $\mathrm{PC}$ & 0.10 & - & + & 3.0 & 0.000 & 0.00 \\
\hline
\end{tabular}

$\dagger$ Average number of birds censused per kilometer, 1988 and 1989 data pooled.

\$ Relative degree of reliance on $P$. mahaleb fruit for food (scored from extensive reliance (•••) to sporadic consumption (•) (Obeso 1987a, b; P. Jordano, unpublished observations).

$\S$ Average number of visits/10 h, 1988 and 1989 data pooled;,$+<0.01$ visits/10 h.

II Average proportion of the seeds handled per visit that are removed from the parent tree.

\section{Postfeeding exit flights}

Availability of microhabitats.-The frequency profile of available microhabitats characterizes an open area rich in rocky substrates, with sparse, scattered patches of mid- and low shrubs and pine forest edges. Open microhabitats made up $66.4 \%$ of the sampled points (deep soil, 19.7\%; gravelly soil, $17.9 \%$; stones on soil, $8.3 \%$; and rock, boulders, and rock substrate, 20.6\%). Microhabitats with plant cover (beneath Prunus, $6.6 \%$; low shrubs, $10.4 \%$; midheight shrubs, $3.3 \%$; high trees, $10.9 \%$; and high trees above low shrubs, $2.4 \%$ ) represented only one-third of the sampled points $(33.6 \%)$.

Destinations of exit flights from the feeding trees.We considered only the seven main frugivore species, for which we have adequate data on visitation records, feeding rates, and flight observations; they included $E$. rubecula, Ph. ochruros, S. cantillans, S. communis, S. europaea, T. merula, and T. viscivorus. Taken together, these seven species accounted for $81.8 \%$ of all seeds dispersed, as estimated from visit records, mean number of fruits handled per visit, and probability of dispersing a handled seed. A total of $86.1 \%$ of the departure flights recorded were to microhabitats with plant cover. Taken individually, microhabitat use by these representative species of the frugivore assemblage differed significantly from the expectation based on availability $\left(\chi^{2}>15.7, \mathrm{df}=1, P<0.0001\right.$, for all possible comparisons). Open microhabitats were used much less frequently than expected, while microhabitats with plant cover, especially $P$. mahaleb, midshrubs, and Pinus were strongly preferred (see Fig. $3 ; \chi^{2}=$ 21.1 , df $=1, P<0.0001$, for the contrast of "open" vs. "covered" microhabitats; CATMOD procedure, SAS Institute 1988).

We used the analysis of frequencies in the species $\times$ microhabitat contingency table to assess preference patterns in the postfeeding exit flights of each species (i.e., cell combinations that exhibit large residuals, differing significantly from expected value). Individual bird species showed distinct tendencies to use particular microhabitat types (Fig. $3 ; \chi^{2}=231.2$, df $=7, P$ $<0.0001)$. Examination of residual cell frequencies for the log-linear model incorporating species and microhabitat effects (Fig. 3) reveals that most species flew to microhabitats with plant cover more often than expected, while avoiding open microhabitats. An exception was $P$. ochruros, which disproportionately flew to and perched on rocks. The significant, overall, preference for Pinus was due to very large numbers of $T$. viscivorus flying to pines; despite the overall pattern, most species avoided Pinus and frequently flew to low or midshrubs or another P. mahaleb tree (Fig. 3). As a consequence, microhabitat types differed significantly in the relative frequencies with which bird species used them; i.e., the identity and relative frequency 

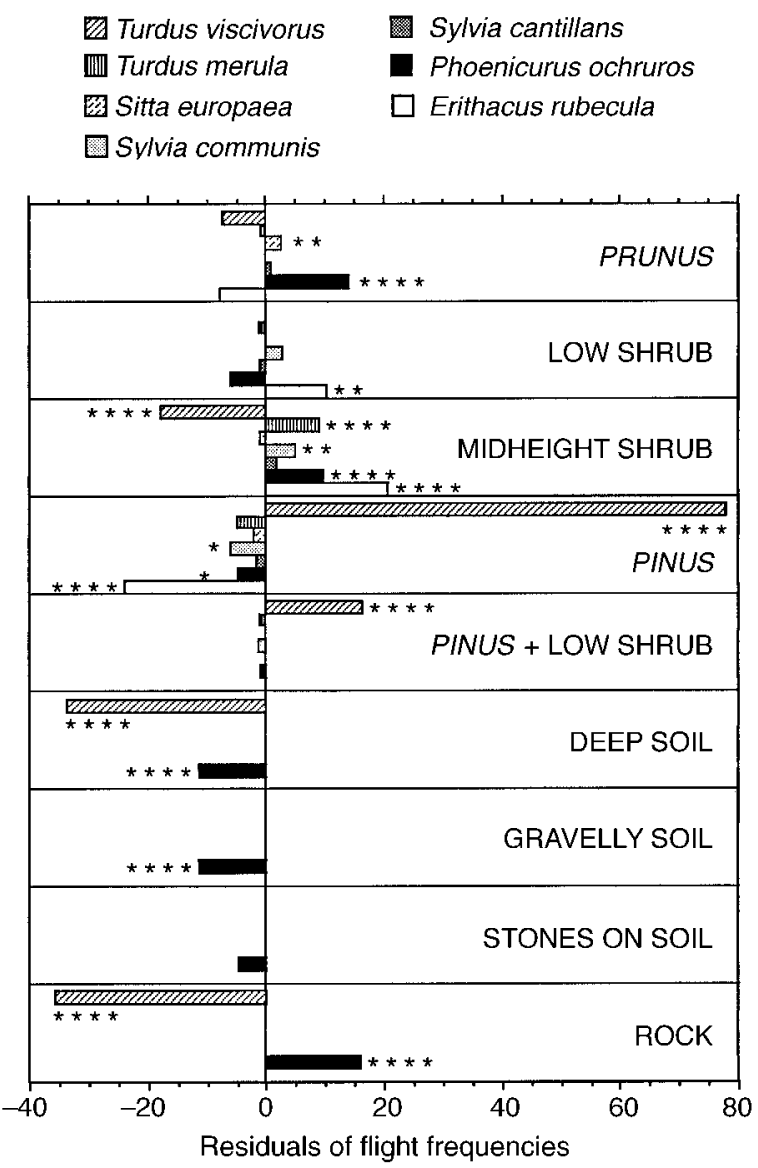

FIG. 3. Residuals of a contingency-table analysis including bird species and microhabitat type. Individual bars depict residual frequencies and their significance, indicating microhabitats favored (positive significant residuals) or avoided (negative significant residuals) by each bird species. Combinations of species and microhabitats without bars indicate lack of use of that particular microhabitat by the bird species. $* P<0.05$; ** $P<0.01$; **** $P<0.0001$.

of bird species flying to different microhabitats differed significantly $\left(\chi^{2}=61.3\right.$, df $\left.=8, P<0.0001\right)$.

Flight distances.-Bird species included in Fig. 3 also differed significantly in distances flown to the first perch after leaving the feeding trees $\left(\chi^{2}=197.8\right.$, df $=$ $12, P<0.0001)$. Most flights were for short distances ( $77.5 \%$ to perches located within $30 \mathrm{~m}$ ). Only the two Turdus species flew longer distances with some frequency $(60.2 \%$ of the flights by $T$. viscivorus and $4.3 \%$ by $T$. merula to distances $>30 \mathrm{~m}$ ). The remaining species usually perched within $15 \mathrm{~m}$ of the feeding tree ( $>50 \%$ of the flights recorded).

Similarly, bird species included in Fig. 3 differed significantly in the distance from the first perch used after feeding and the nearest $P$. mahaleb tree whether or not it was the feeding tree $\left(\chi^{2}=159.7\right.$, df $=12, P$ $<0.0001)$. For all species except the two Turdus, most exit flights $(>92.0 \%)$ were to perches within $15 \mathrm{~m}$ of a $P$. mahaleb tree. Thus, whether or not the first perch used after feeding on fruits was a $P$. mahaleb tree, and independent of distance flown, most birds feeding on Prunus tended to perch close to Prunus trees. Turdus viscivorus, however, rarely flew to perches $<5 \mathrm{~m}$ from a $P$. mahaleb tree (1.9\% of the flights), and generally flew to perches $>15 \mathrm{~m}$ away from the nearest Prunus tree. Some exit flights by Ph. ochruros $(7.5 \%), S$. communis $(4.5 \%)$, and T. merula $(4.3 \%)$ were also to perches $>15 \mathrm{~m}$ away from the nearest Prunus. Pooling data for all bird species (those included in Fig. 3), 40.3\% of the exit flights were to perches $>15 \mathrm{~m}$ away from the feeding tree, but only $18.5 \%$ of these flights were to perches $>15 \mathrm{~m}$ from any $P$. mahaleb.

\section{Seed rain}

Correlates of spatial variation in seed rain.-The overall number of seeds dispersed per square meter was similar in 1988 and 1989 (23.1 \pm 3.4 seeds dispersed/ $\mathrm{m}^{2}, 1988 ; 18.4 \pm 3.3$ seeds dispersed $/ \mathrm{m}^{2}, 1989 ; F=$ 1.93, df $=1,252, P=0.1660)$. Microhabitats differed significantly in seed rain density (Fig. 4) $(F=34.65$, $\mathrm{df}=8,252, P<0.0001)$ and there were differences in seed rain between years for particular microhabitats ( $F=2.31, \mathrm{df}=8,252, P=0.021$, for the microhabitat $X$ year interaction; see Fig. 4$)$. Covered microhabitats received significantly more seeds $(39.3 \pm 5.0$ seeds dispersed $/ \mathrm{m}^{2}, 1988 ; 31.7 \pm 5.9$ seeds $\operatorname{dispersed} / \mathrm{m}^{2}$, $1989)$ than open microhabitats $(2.8 \pm 0.7$ seeds dispersed $/ \mathrm{m}^{2}, 1988 ; 1.8 \pm 0.4 \mathrm{seeds}$ dispersed $\left./ \mathrm{m}^{2}, 1989\right)$ ( $F>30.0, \mathrm{df}=1,134, P<0.0001$, for the contrasts between the two groups of microhabitats in the comparisons for 1988 and 1989). In 1988, both the Prunus and high-trees (Pinus) microhabitats showed significantly greater seed rain than any other microhabitat in the two years. In 1989, Prunus received the greatest seed rain, followed by midheight shrubs and high-trees (Pinus) microhabitats (Fig. 4).

We analyzed the correlates of seed rain intensity in each replicate group of traps or quadrats by means of a linear model incorporating the effects of microhabitat type and quantitative habitat variables including the distance to, and basal stem diameter of, the nearest Prunus (NEARPRU and BSD, respectively), distance to nearest cover of shrubs with branches $<50 \mathrm{~cm}$ above ground (DISTCOV), number of Prunus trees with at least one branch within a $10-\mathrm{m}$ radius (NUMPRU), and estimated fruit crop size of these nearby trees (CROPNEIG). For both years, the fitted model explained a significant proportion of variation in seed rain $\left(R^{2}=\right.$ $0.7320, F=25.42, \mathrm{df}=13,121, P<0.0001,1988$; $R^{2}=0.6953, F=21.24, \mathrm{df}=13,121, P<0.0001$, 1989; Table 7). The type of microhabitat was the best predictor of seed rain density at a particular patch, with a significant effect in both years $(F \geq 22.3$, df $=8$, 126, $P<0.0001$; Table 7). Among the quantitative habitat variables characterizing the neighborhood of each trap replicate, only NEARPRU $(F \geq 5.0, \mathrm{df}=1$, $133, P<0.026)$ and BSD $(F \geq 6.2$, df $=1,133, P<$ 


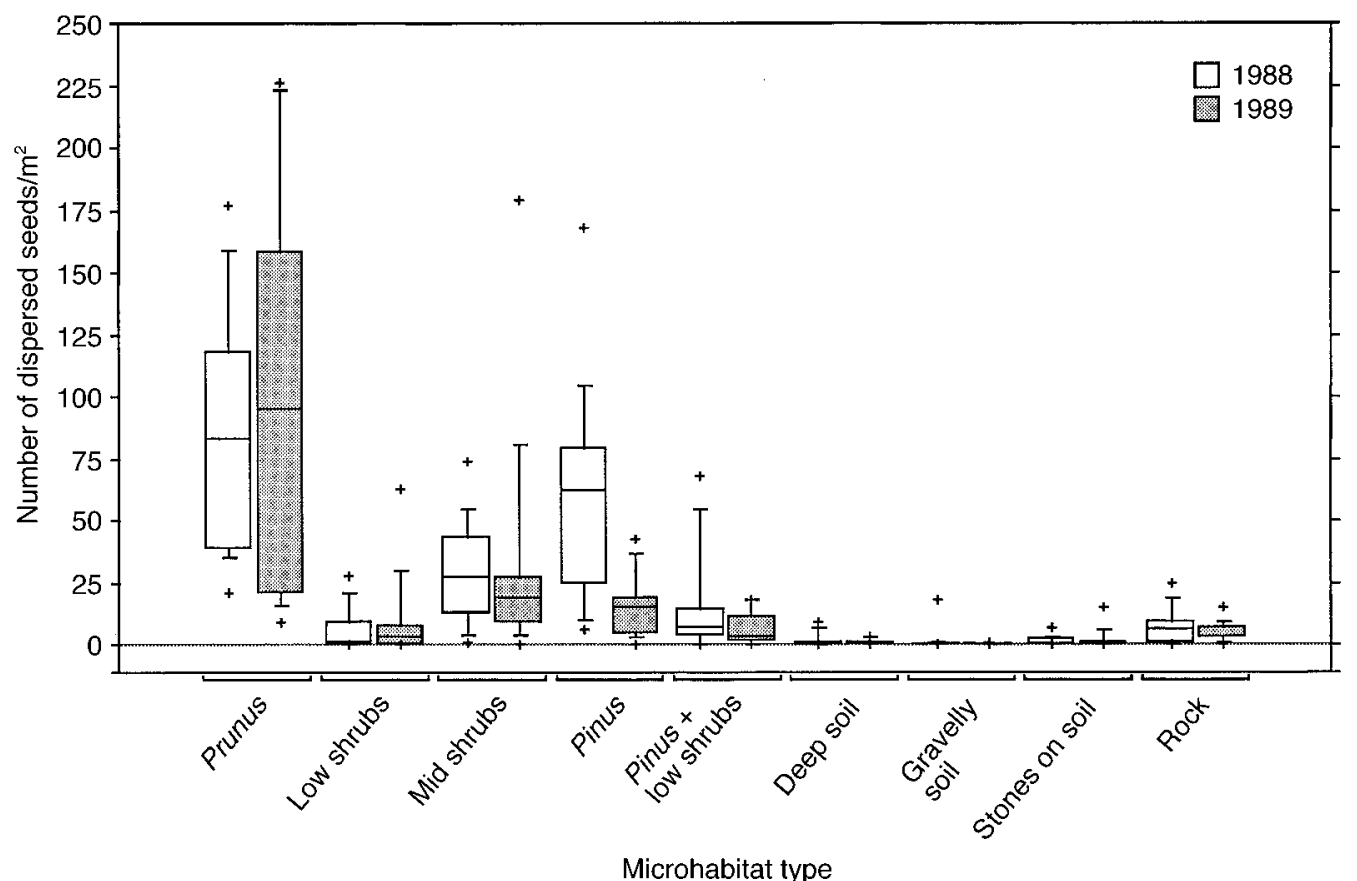

FIG. 4. Box plots of estimated viable Prunus mahaleb seedfall to different microhabitat types in 1988 and 1989. Horizontal lines show the medians, vertical boxes span the first and third quartile range, vertical lines span the 10-90\% range, and crosses depict extreme values. $N=135$ seed traps or sampling quadrats/year. Median seedfall was $6 \mathrm{seeds} / \mathrm{m}^{2}(0-28 \mathrm{seeds} /$ $\mathrm{m}^{2} ; 25-75 \%$ quantiles $)$ in 1988 and 3 seeds $/ \mathrm{m}^{2}\left(0-16\right.$ seeds $\left./ \mathrm{m}^{2}\right)$ in 1989.

0.01) had significant effects in either year. The distance effect was evident only in 1989, with seed rain density decreasing with increasing distance from Prunus trees. In both 1988 and 1989, there was a positive correlation between the BSD of the nearest Prunus tree and seed rain density at a particular patch (Table 7).

The significance of distance to the nearest Prunus, and the size of the nearest Prunus, could be artifacts of including the data from traps beneath Prunus, since
NEARPRU $=0 \mathrm{~m}$ for this microhabitat type by definition. Thus, a "distance" effect could be due simply to Prunus microhabitats having a distance equal to 0 and a greater seed rain density than any other microhabitat (Fig. 4). Consequently, we also fit a multiple regression model incorporating only the quantitative habitat variables (NEARPRU, BSD, DISTCOV, NUMPRU, and CROPNEIG), separately for 1988 and 1989, and excluding the data from traps beneath Prunus trees

TABLE 7. Effect of habitat characteristics surrounding the seed traps on seed rain density of Prunus mahaleb (number of seeds $/ \mathrm{m}^{2}, \log$ transformed) in 1988 and 1989.

\begin{tabular}{|c|c|c|c|c|c|}
\hline \multirow[b]{2}{*}{ Source of variation } & \multirow[b]{2}{*}{ df } & \multicolumn{2}{|r|}{1988} & \multicolumn{2}{|r|}{1989} \\
\hline & & GLM & $\operatorname{MR}(\beta) \dagger$ & GLM & $\operatorname{MR}(\beta) \dagger$ \\
\hline Microhabitat type & 8 & $31.92 * *$ & $\ldots$ & $22.25 * *$ & $\ldots$ \\
\hline Distance to nearest Prunus & 1 & $2.38^{\mathrm{NS}}$ & $-0.047^{\mathrm{NS}}$ & $7.21 * *$ & $-0.059 * * *$ \\
\hline Basal stem diameter of nearest Prunus & 1 & $8.88 * *$ & $0.003^{\mathrm{NS}}$ & $6.50 * *$ & $0.002^{\mathrm{NS}}$ \\
\hline $\begin{array}{l}\text { Distance to nearest shrub vegetation } \\
\text { cover }\end{array}$ & 1 & $127 \mathrm{NS}$ & $0064 * *$ & $035 \mathrm{NS}$ & $0057 * *$ \\
\hline $\begin{array}{l}\text { Number of Prunus trees within } 10 \mathrm{~m} \\
\text { Fruit crop size of Prunus trees within }\end{array}$ & 1 & $0.02^{\mathrm{NS}}$ & $-0.064^{\mathrm{NS}}$ & $\begin{array}{l}0.35^{\mathrm{NS}} \\
2.28^{\mathrm{NS}}\end{array}$ & $-0.042^{\mathrm{NS}}$ \\
\hline $\begin{array}{l}10 \mathrm{~m} \\
\text { Error }\end{array}$ & $\begin{array}{r}1 \\
121\end{array}$ & $0.12^{\mathrm{NS}}$ & $0.18 \times 10^{-5} \mathrm{NS}$ & $0.05^{\mathrm{NS}}$ & $0.72 \times 10^{-6 \mathrm{NS}}$ \\
\hline
\end{tabular}

Note: For each year, results are given for the general linear model (GLM; $F$ values and significance) incorporating the effect of microhabitat type and five quantitative variables describing the habitat surrounding each replicate set of traps, as well as those from a multiple regression (MR; randomization test) analysis of the quantitative variables (parameter estimate $[\beta]$ and significance). The traps located beneath Prunus were excluded from the multiple regression analysis (distance to nearest Prunus $=0 \mathrm{~m}$, by definition).

$\dagger$ Coefficient estimate $(\beta)$, and significance value, obtained by randomization, for the extra sums of squares accounted for by each variable with the remaining variables already in the model (Manly 1991). ** $P<0.01$; *** $P<0.001$; NS $=$ not significant. 


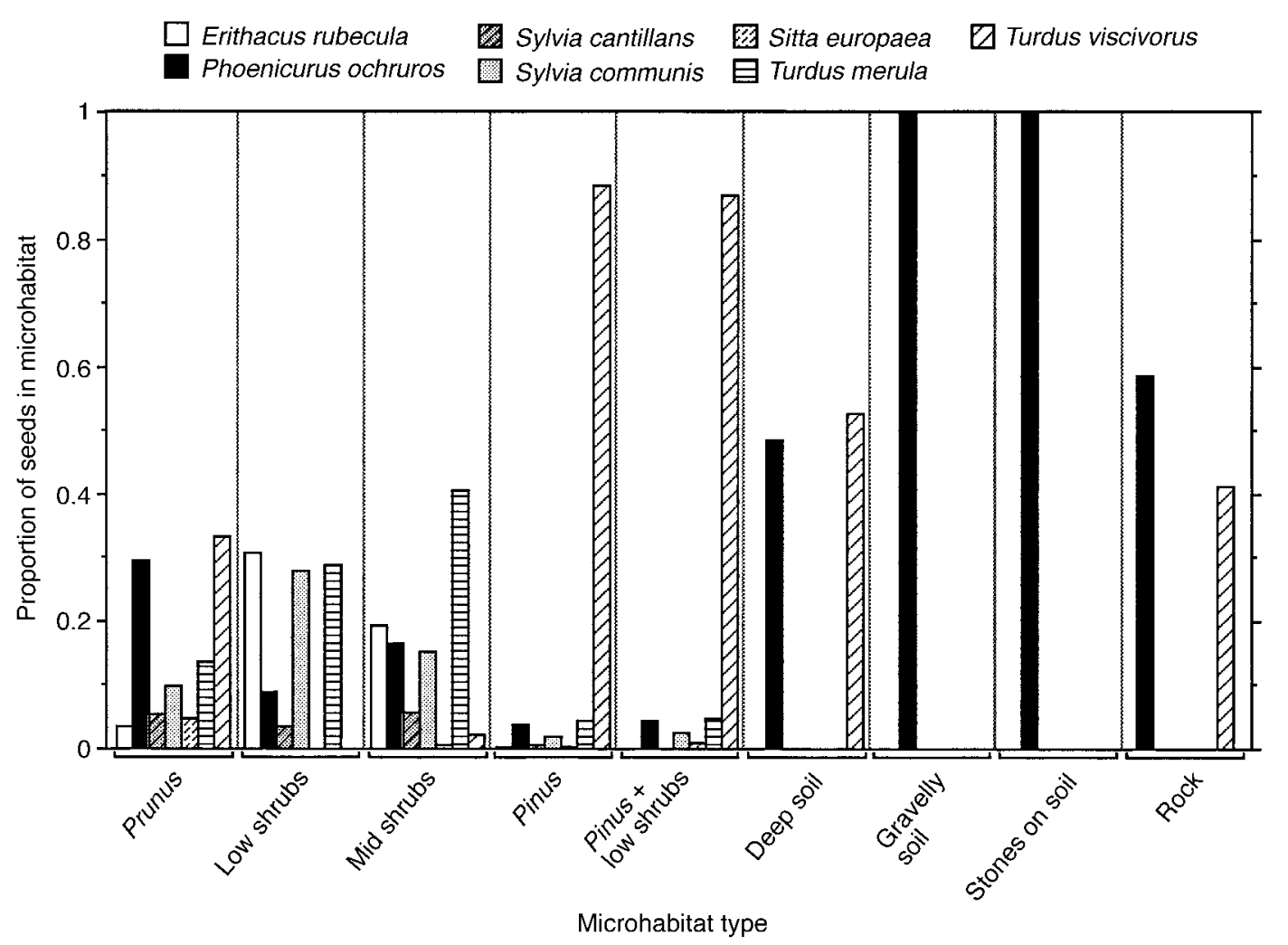

FIG. 5. Estimated proportion of seedfall to each microhabitat type contributed by the main frugivore species visiting Prunus mahaleb trees. Bars depict the relative contribution of each species to the total seed rain (contributed by all seven species) in a particular microhabitat. Estimates derived from visitation records, number of fruits handled per visit, and probability of dispersing a handled seed indicate that these seven species contributed $81.8 \%$ of all the seed rain in the two study years.

(Table 7, column $\beta$ ). The models were still significant but explained a much lower fraction of variance in seed rain than the one including the effect of microhabitat type $\left(R^{2}=0.1006,1988 ; R^{2}=0.1558,1989\right)$. For both years the model had only DISTCOV with significant effects, and BSD, NUMPRU, and CROPNEIG with insignificant effects (Table 7). The seed rain falling in a particular trap or quadrat replicate set decreased with increasing distance either to nearest shrub cover or to nearest Prunus in both years.

To summarize, the seed rain received by a given patch was strongly associated with the microhabitat type of the patch and increased in the neigborhood of Prunus trees and understory cover, but was unrelated to fruit production or size of Prunus trees in the vicinity of the patch.

Contribution of frugivore species to the seed rain in microhabitats. - The potential contribution of each of the seven main bird species to the seed rain in each microhabitat was estimated from the number of visits recorded, the mean number of seeds dispersed from a tree per visit, and the proportion of exit flights to each microhabitat. We first calculated the contribution of each frugivore species to the total seed rain. We pooled the data from the two study years, and multiplied the number of visits recorded for each species by the mean number of seeds dispersed per visit. The number of seeds delivered to each microhabitat was obtained, for each species, by multiplying these total numbers of seeds by the proportion of flights to each microhabitat. The number of seeds delivered to microhabitat $i$ by bird species $j$ relative to the total number of seeds delivered to $i$ by all seven species yields the proportional contribution of species $j$ to the seed rain in $i$.

Microhabitats differed strongly in the proportions of seeds contributed by the main frugivores (CATMOD procedure, SAS Institute 1988; $\chi^{2}=2644.1, P<$ 0.0001 , Fig. 5), and bird species also differed in the proportions of seeds contributed to a given microhabitat $\left(\chi^{2}=5048.7, P \ll 0.0001\right.$, Fig. 5). In particular, "open" and "covered" microhabitats differed significantly in the proportional contribution to their seed rain by the different bird species. The seed rain to covered microhabitats was delivered by a more heterogeneous assortment of species than the seed rain to open sites (Fig. 5). For example, seeds dispersed to "stones on soil," "rock," or "gravelly soil", sites were dispersed mainly by Redstarts (Ph. ochruros), while no single species contributed $>45 \%$ of the seed rain to 
"mid-height shrubs," "low shrubs," or "Prunus" microhabitats.

We examined the significance of the patterns depicted in Fig. 5 by fitting a log-linear model (CATMOD procedure, SAS Institute 1988) incorporating the microhabitat and species effects. The significance of the residuals from this model can be used to identify those disperser $\times$ microhabitat combinations that depart from the seed rain expected on the basis of the relative abundances of both microhabitat types and birds. Most species dispersed fewer seeds than expected to the deep soil and gravelly soil substrates lacking woody vegetation cover; only Ph. ochruros showed residuals consistently positive and significant in these microhabitats ( $\left.\chi^{2} \geq 20.0, P<0.007\right)$. The remaining species either did not use these microhabitats (Fig. 5) or did so much less frequently than expected (e.g., T. viscivorus on rocks, $\left.\chi^{2}=109.1, P<0.0001\right)$. Most species, with the exception of $T$. viscivorus, dispersed no or few seeds to the pine forest microhabitats ("high trees (Pinus)", and "high trees (Pinus) plus low shrubs" combined) and showed significant negative residuals.

\section{Discussion}

A simple, heuristic definition of effectiveness is the contribution dispersers make to plant fitness (Schupp 1993), and depends on both the quantity of seeds dispersed (quantity component) and the probability a dispersed seed will recruit a new reproductive adult (quality component). Our results concern the quantity component and the multiple factors that influence it.

As can effectiveness itself, the quantity component can be considered from the perspectives of both the dispersal agents and the dispersed plants, and at a variety of scales from individuals to communities. We emphasize variation among bird species (or occasionally functional groups) in the quantity of seeds they dispersed, but we also consider variation among individual trees in the quantity of seeds they had dispersed. Further, we address the patterns of seed rain created by dispersers. By combining these perspectives, we believe we have developed a thorough understanding of seed dispersal and the myriad factors influencing dispersal from fruit production through the microhabitat pattern of seeds on the ground.

Ultimately, the quantity component of disperser effectiveness is limited by fruit crop size; potential maximum effectiveness would be achieved whenever dispersers successfully deliver all the seeds produced, although maximal fitness returns can eventually occur under submaximal disperser effectiveness (e.g., all available "safe sites" are saturated). Thus, from a plant's perspective, both the absolute number of seeds dispersed and the proportion dispersed relative to the fruit crop produced would be important components of success in the interaction with frugivores. We first examine the correlates of fruit removal success in the $P$. mahaleb population and assess the potential of frugi- vore activity to limit seed dispersal for individual trees. We then discuss factors that determine variation among frugivores in both the quantity component of effectiveness and variation in the seed shadows that each species generate. A detailed examination of the quality component of seed dispersal in $P$. mahaleb will be presented elsewhere.

\section{Fruiting, fruit removal, and seed dispersal success}

With similar levels of flowering intensity in the two years, a 2.6-fold decrease in fruit set in 1989 resulted in a near four-fold decrease in ripe fruits available for frugivores, suggesting an added negative effect of increased abortion of unripe fruit in that year. Similar effects of predispersal losses on fruit availability for frugivores have been documented previously for other Mediterranean tree and shrub species (Jordano 1987a, 1989). Our limited two-year data for P. mahaleb suggest that the absolute number of flowers produced did not limit the size of the fruit crop in 1988, when all trees had a large proportion of flowers setting fruit; but under conditions impairing fruit set (e.g., bad weather resulting in low generalized fruit set level), among-tree variation in fruit crop size is best explained by variation in flowering intensity.

Our regression analysis of seed dispersal success revealed a dramatic impact of variation in fruit crop size on among-tree variation in the absolute number of seeds dispersed. This major influence of plant fecundity alone has been reported previously for many species (Davidar and Morton 1986, Herrera 1991, Carr 1992, Sallabanks 1992, Laska and Stiles 1994) and suggests that among-individual differences in rate processes (such as the fraction of flowers pollinated or fraction of ripe seeds dispersed) rarely compensate for differences in absolute numbers (Jordano 1987a, Herrera 1988, 1991); i.e., more fecund plants might disperse a greater absolute number of propagules even if, for example, they have low relative seed dispersal success. In the particular case of $P$. mahaleb, where some fruits are removed by pulp consumer species, differences in seed dispersal success may also result from annual variation in visitation frequency by pulp consumers relative to legitimate seed dispersers (Herrera et al. 1994, Jordano 1994). We were able to account for the negative effect of visitation by nonlegitimate frugivores (PC and PCSD species) on absolute seed dispersal and demonstrate that among-tree differences in visitation rate by these frugivores explained a small, but significant, fraction of the variance in seed dispersal.

Changes in particular frugivore groups at the study site have been documented previously (Jordano 1994), and the reasons behind such interannual changes are not clear. Most species feeding on P. mahaleb fruits breed in the area, and both adults and first-year juveniles of the main consumers (Phoenicurus spp., Turdus spp., F. coelebs, and Parus spp.) were observed at the trees during the postreproductive period coincident 
with $P$. mahaleb fruit ripening (late July- late August). Thus, yearly changes in abundance of these species could be attributable to variations in the size of the breeding population and breeding success (see Obeso 1987 for further discussion). Local breeding populations of $F$. coelebs, the main species contributing to the observed changes among PC frugivores, vary greatly among years (Obeso 1987, Asensio and Carrascal 1990). Variation in the composition of the frugivore assemblage between years thus shows an important effect on population-level seed dispersal success, with greater average relative seed dispersal success in the year with less abundant PC and PCSD species.

Summarizing the main trends, despite a large difference in the initial fruit crop size (Table 1) at the population level, lower fruit loss to nondisperser species in 1989 (greater dispersal success in this year) resulted in similar absolute number of seeds dispersed per tree in the two study years and similar seed fall density. Increased consumption by legitimate seed dispersers thus somewhat compensated the low fruit availability in that year. At the individual tree level, variation in frugivore activity, in particular among-tree variation in visitation by PC and PCSD species, best explained among-tree variation in the fraction of the fruit crop that was successfully dispersed (see longer term data in Jordano 1994); however, among-tree variation in the absolute number of seeds dispersed was more strongly dependent on the initial number of ripe fruits produced.

\section{Dissecting the quantity component of effectiveness}

No factor influencing the quantity component of effectiveness (Table 6) can adequately estimate it alone (Schupp 1993). All need to be assessed when evaluating the effectiveness of different frugivore species.

Visitation.-The strongest correlate of visitation rate by a frugivore species is its abundance in the area, and our results indicate that, for frugivores that consume $P$. mahaleb fruits, census records are crude predictors of visitation frequency at the trees. The overall picture for the frugivore assemblage of $P$. mahaleb is of high reliability in terms of species composition and relative abundance. First, there was no significant species $\times$ year interaction in the ANOVA analysis of betweenyear variation in frugivore abundances; second, the composition of bird assemblages visiting individual trees varied among trees, but was consistent between the two study years. Most likely this high reliability of the frugivores is related to the fact that birds visiting $P$. mahaleb are largely locally breeding species. Longterm census data at this site (Jordano 1994; P. Jordano, personal observation) reveal a high among-year consistency in the composition of the local avifauna. Although annual variations certainly exist, as shown by shifts in the abundances of major groups of frugivores (see Results: Bird abundance), the relative magnitude of variation is much lower than reported for frugivore assemblages composed chiefly of migratory or nonbreeding birds (Herrera 1984, Jordano 1985, Jordano 1993a, Herrera 1998).

Variation among frugivore species.-Between-year changes in the abundance and feeding records of the most frequent SD visitors to the trees ( $P$. ochruros, $T$. viscivorus, E. rubecula, and $S$. communis) were small, but species differed significantly in visitation rate. These species, together with $T$. merula and, among PC species, $P$. ater and $F$. coelebs, are locally dominant at mid- and high-elevation sites within the general study area just after the breeding season, when ripe $P$. mahaleb fruits are available (Obeso 1987, P. Jordano, personal observation). The largest between-year variations in abundance were recorded for the PC species $P$. ater and $F$. coelebs, as was also reported previously for lower elevation sites (Obeso 1987).

Consequences for the trees of variation in visit rate by different frugivore groups.-Between-year changes in the composition of the frugivore assemblage had an effect on overall fruit removal rates in the two years, but effects of among-tree differences in composition were far more dramatic. Visits by SD species ranged from 19 to $92 \%$ of the total visits by frugivores to individual trees, and this variation had a large effect on potential seed dispersal success. More importantly, these individual differences tended to be consistent between years, suggesting an important long-term impact on dispersal success of individual trees if some trees consistently receive visits by SD species while others are consistently visited by PC species. Differences in the composition of the frugivore assemblages among individual plants have only rarely been reported previously (Herrera and Jordano 1981, Traveset 1994) and their consequences have never been addressed in detail. In the present study, we found that among-tree variation in the proportion of visits by the three frugivore groups accounted for $54 \%$ of the variation in relative seed dispersal success, and that the positive effect on seed dispersal success of visitation by SD species was greater than the negative effect of visitation by PC species, probably because of the greater feeding rates of SD species. By focusing on individual tree variation, our results demonstrate not only that some trees consistently received very few visits by frugivores while others were visited frequently, but also that different trees consistently received visits by distinct combinations of $\mathrm{SD}, \mathrm{PC}$, and PCSD groups.

Fruit foraging and fruit handling.-Together with visitation frequency, fruit handling behavior, especially feeding rate, is the major correlate of the quantitative importance a given frugivore has for a plant species. Frugivores visiting fruiting plants typically differ widely in feeding rates (e.g., McDiarmid et al. 1977, Howe and Vande Kerkchove 1981, Jordano 1983, Snow and Snow 1988; see Schupp 1993 for review) but it remains to be seen if a high feeding rate can eventually compensate for a lower visitation rate. At least for P. ma- 
haleb, variation in feeding rate did not compensate for variation in visitation rate. Rare visitors with high feeding rates (e.g., Columba palumbus) had a lower quantity component than more frequent visitors with slow feeding rates (e.g., Fringilla coelebs) (also see Sun et al. 1997). In general, the total quantity of seeds dispersed correlates better across species with number of visits than with number of seeds dispersed per visit (Schupp 1993, for a review), and our results support this generalization.

What aspects of foraging best explain variation in seeds dispersed per visit? For a given visitation rate, frugivores feeding on $P$. mahaleb fit neatly into three distinct types of fruit-handling behavior that affect the probability that a handled seed will be dispersed away from the plant. First, PC species just peck pulp pieces and drop seeds beneath parent canopies, thus dispersing no seeds (with the exception of F. coelebs, which on extremely infrequent occasions takes a fruit in its bill and leaves the tree). Second, PCSD species are very similar to PC species except that they carry fruits away from the parent on occasion, and in the process disperse a small fraction of the seeds handled; in this group, only $S$. europaea disperses $>14 \%$ of handled seeds. Finally, SD species swallow fruits whole and thus generally disperse most handled seeds, although species vary greatly in the probability of dispersing a handled seed (0.182-1.000). This variation among SD species is largely attributable to size differences, especially gape width, and resulting variation in fruit-handling success. This is evident among the Sylvia warblers, where the mean percentage of fruits dropped during feeding bouts was negatively correlated across species with mean gape width (see also Jordano 1987b).

But despite these differences, resulting variation in probability of dispersing a seed handled among SD species was much smaller $(>0.80$ for all species of the two smaller Sylvia warblers, Table 6) than the differences between SD and PC-PCSD species (the latter showed $<0.40$ probability of dispersing a handled seed). These broad differences among frugivore categories most likely reflect the large differences in feeding modes among "gulpers" and "mashers" (Foster 1987, Levey 1987), the two major feeding types among frugivorous birds (Jordano 1992). Finches and tits feeding on $P$. mahaleb fruit exhibit a similar feeding pattern to typical "mashers" like neotropical tanagers and finches, with relatively long fruit-handling times and low overall feeding rate (Trainer and Will 1984, Levey 1986, Foster 1987, Levey 1987). All SD species show a characteristic "gulper" behavior, with the overall feeding rate more directly limited by the type of foraging maneuver used to pluck the fruits. Birds taking fruits while perched on branches, like warblers, had high feeding rates with extremely short handling times, short stopping times, and rapid movements in search of fruits. In contrast, birds taking fruits on the wing, like the Robin and Redstarts, have slower feeding rates linked to long "stopping" times between successive fruit "captures." The gulper/masher dichotomy helps to explain major differences in fruit handling among major frugivore types and shows many correlates with other aspects of frugivore activity that ultimately influence effectiveness. However, differences among species within the same category (e.g., among SD species) is best explained by variation in foraging maneuvers (e.g., gleaning fruits from branches vs. taking the fruits on the wing), especially if differences in body size are accounted for.

\section{Patterns of seed delivery and the seed shadow}

A given seed disperser species has a characteristic seed delivery pattern, which depends on the total amount of seed dispersed (its relative contribution to the total final seed rain reaching the ground) and the spatial distribution of this contributed seed rain. This distribution obviously has a distance component, which most analyses of animal-mediated seed dispersal emphasize (Willson 1993). Perhaps more important in many systems, however, is the distribution of seeds across the distinct patch types making up the landscape. It is well documented that, in general, frugivore activity results in extremely heterogeneous seed shadows (Debussche et al. 1982, McDonnell and Stiles 1983, Hoppes 1987, Hoppes 1988, Izhaki et al. 1991, Debussche and Isenmann 1994, Kollmann and Pirl 1995, Kollmann and Schneider 1996, Loiselle et al. 1996). Most studies, however, have emphasized the description of the final seed shadow generated by the whole array of dispersers (Debussche et al. 1985, Holthuijzen and Sharik 1985, Alvarez-Buylla and Martínez-Ramos 1990, Clergeau 1991, Martínez-Ramos and Soto 1993, Chávez-Ramírez and Slack 1994, Debussche and Isenmann 1994, Sargent 1995, Kollmann and Schneider 1996) or concentrated on particular species (Howe and Primack 1975, Murray 1988, Mack 1995, Sun et al. 1997). Few have attempted a comparative analysis of the main frugivores that disperse a plant (Reid 1987, Katusic-Malmborg and Willson 1988, Reid 1989, Schupp 1993, Graham et al. 1995, Larson 1996) or addressed explicitly the problem of quantifying disperser effectiveness. Every frugivore species has a species-specific pattern of seed delivery that, to the extent microhabitat patches differ in suitability for plant recruitment, will largely control variation in the quality of dispersal.

Direct effects on seedfall intensity.-Ultimately, among-year variation in density of dispersed seed (number of seeds per square meter) can be caused by variation in the number of fruits produced by the plants, by variation in the abundance of frugivores, by changes in seed dispersal success, or by a combination of these three factors. Our study demonstrates that increased abundance of legitimate seed dispersers resulted in a generalized increase in the fraction of the seed crop successfully dispersed away from individual trees. De- 
spite a dramatic decrease in fruit availability in 1989 (Table 1), seed rain density, estimated by seed trap and quadrat data, was similar in 1988 and 1989 (means of 23.1 and $18.5 \mathrm{seeds} / \mathrm{m}^{2}$, respectively). The greater relative seed dispersal success in 1989, that resulted from a lower abundance of PC species and a greater abundance of SD species, somewhat compensated for the reduction in fruiting intensity. Documenting both absolute and relative fruit removal and the fraction of it that results in seed dispersal is thus necessary to adequately assess the potential of frugivores to limit plant recruitment.

The seed shadow: patterns of differential delivery to microhabitats.-Variation among microhabitat types in the number of dispersed seeds per square meter largely reflected variation in the relative frequency of flights received by each particular microhabitat. The resulting seed shadow was therefore a complex result of the interaction between the movement patterns of a suite of bird species differing in microhabitat preferences and the specific landscape distribution of these microhabitat patches. Previous studies have pointed out the relevance of fruiting conspecifics (Herrera and Jordano 1981, Denslow 1987, Hoppes 1987, 1988, Murray 1988, Sargent 1990, Izhaki et al. 1991, Sallabanks 1993) in influencing the postforaging movements of frugivores. We emphasize that beyond the "fruiting environment" surrounding a plant, the overall assortment of physiognomically distinct patches in the surrounding landscape influences the postforaging movements of frugivores, the landscape pattern of seedfall, and ultimately the quality of dispersal performed by each frugivore species.

From a plant's perspective, a seed shadow is an array of survival probabilities for the seeds produced in a reproductive event. For animal-dispersed species this array is directly determined, assuming no secondary dispersal, by the activity patterns of frugivores. The continuous array of survival probabilities is generated by the interaction of microhabitat preferences of the frugivores while foraging with the suitabilities of these microhabitat patches for germination, seedling emergence and establishment, and survival and growth to adulthood. Critical characteristics of the seed shadow generated by a particular frugivore species are the total amount of seed dispersed, the distribution of these seeds among patches that differ in suitability for establishment, and the distribution of distances from maternal plants. By combining detailed observations of habitat use by the birds with extensive sampling of seed rain density we were able to assess these components of the $P$. mahaleb seed shadow.

Distance effects are important in seed dispersal not only because they influence aspects like the colonizing ability (Willson 1993), but because survival and growth of propagules (seeds or seedlings) frequently depend on distance to conspecifics and/or density effects (Clark and Clark 1984, Howe et al. 1985, Webb and Willson
1985, Schupp 1988, Fleming and Williams 1990, Willson and Whelan 1990, Willson 1992). For P. mahaleb, density of dispersed seed increased in the vicinity of Prunus trees, although it was unrelated to tree size or fruit crop size, at least within the range of tree sizes considered $(>10 \mathrm{~cm} \mathrm{dbh}$, large enough to exceed 1000 fruits). The distance effect was due to the fact that most exit flights were to short distances $(<15 \mathrm{~m}$, and in most cases, $<5 \mathrm{~m}$ ). The strong preferences of bird species for particular microhabitats was, however, the major cause of the highly spatially heterogeneous seed shadow. In particular, microhabitats with woody cover, representing only $\sim 33 \%$ of the total cover, received nearly $86 \%$ of total exit flights and $96 \%$ of total seed rain. Combined with the significant distance effect, this suggests a seed shadow concentrated beneath woody vegetation in the neigborhood of adult Prunus trees. This seems to be a general pattern in Mediterranean and Central European forest and scrubland, where similar patterns have been reported previously (Debussche et al. 1985, Izhaki et al. 1991, Herrera et al. 1994, Kollmann and Pirl 1995, Kollmann and Schneider 1996, Verdú 1996, Kollmann and Poschlod 1997). It is noteworthy, however, that the activity, flight, and seed delivery patterns of the two main $P$. mahaleb seed dispersers, T. viscivorus and Ph. ochruros, depart markedly from this dominant pattern. The former frequently fly long distances after feeding, while the latter intensively use rock outcrops.

Our results suggest that in many cases it is important to consider not only dispersal distance, but also the resulting distance from dispersed seeds to nearest conspecific trees. Although dispersal distances influence genetic structure of the population, distance to a conspecific is likely a better determinant of seed and seedling fate. In this study, birds tended to perch close to another Prunus, irrespective of distance flown, a tendency related to bird preference for covered microhabitats and the frequent presence of Prunus trees in these types of patches. Mack (1995) has also addressed this important distinction. In our study system it is clear that different Prunus trees not only differ in seed dispersal success, but also in their role in attracting the seedfall from other conspecifics.

Differences among microhabitat types in the density of dispersed seeds were large, as expected based on previously documented responses of avian frugivores to habitat heterogeneity (Bairlein 1981, Herrera and Jordano 1981, Willson et al. 1982, Martin and Karr 1986, Katusic-Malmborg and Willson 1988, Blake and Loiselle 1991, Izhaki et al. 1991, Loiselle and Blake 1993, Kollmann and Pirl 1995). Our study is one of the few to demonstrate that not only do frugivorous birds use particular microhabitat types far more or less frequently than expected based on their relative availability (e.g., Herrera and Jordano 1981), but also that different species use different combinations of microhabitat types (see also Izhaki et al. 1991). Therefore, 
the bird-generated seed shadow for $P$. mahaleb is extremely nonrandom, due to both a strong overall preference by most of the birds for the relatively scarce covered microhabitats, and to species-specific preferences for particular types of covered microhabitats. Different microhabitat types not only received variable amounts of dispersed seed, but also differed in the number and identity of disperser species contributing to that seed rain. Consequently, year-to-year and site-tosite differences in the avian frugivore community will lead to potentially large differences not only in the number of seeds dispersed, but also in the microhabitat distribution of the seed shadow. If microhabitats differ in the suitability to Prunus recruitment, different disperser assemblages may have very different effects on plant recruitment independent of the quantity of seed dispersed.

Differential habitat use by avian frugivores during the postforaging movements has been reported previously (Herrera and Jordano 1981, Willson et al. 1982, Hoppes 1987, Katusic-Malmborg and Willson 1988, Izhaki et al. 1991, Wenny and Levey 1998), although it has been related generally to distinct dichotomous habitat types (understory vs. canopy, gap vs. forested habitat, etc.). No broad generalizations can be made as to the effect of woody plant cover on density of dispersed seed, as the type of habitat preference is extremely site (bird species) specific. Thus, covered sites received greater $P$. mahaleb seed input than open places, yet Hoppes (1987) reported the lowest seedfall in forest interior (also see Katusic-Malmborg and Willson 1988). Moreover, some species with a relatively broad range of microhabitat use in this study (e.g., blackbirds) have been reported to use a narrower range of microhabitats in other Mediterranean shrublands (Izhaki et al. 1991). At least for Mediterranean high-elevation sites (and probably for mountain xeric habitats with an important component of open ground), an important distinction among the frugivorous birds is between those that forage in relatively dense shrubby cover (e.g., Sylvia, T. merula, Parus spp.) and those that also forage frequently in open sites like rocky places and grassy ground (Phoenicurus spp., T. viscivorus).

An additional marked difference between covered and open microhabitats is that they differed greatly in the number of disperser species that contributed to the seed rain. Covered patches received seed delivered by 7-11 bird species, while the seeds arriving in open patches were contributed by only 1-2 species (Phoenicurus spp. and T. viscivorus). Even within covered or open microhabitats, differences in which species deliver seeds were marked. Pine sites, for example, were chiefly selected by $T$. viscivorus and only rarely received flights by other dispersers. It is worth noting that the two pine-covered microhabitats concentrated a sizeable fraction of the $P$. mahaleb seed shadow, despite being avoided by most dispersers, because $T$. viscivorus disperse far more seeds than any other spe- cies in the frugivore assemblage. The situation for the rock microhabitat is similar, with Phoenicurus spp. contributing most of the dispersed seed.

A strong potential for genetic or other (e.g., competitive) consequences due to this heterogeneous pattern of seed delivery can be envisioned (see, e.g., Loiselle et al. 1995, Alvarez-Buylla et al. 1996, Bruederle et al. 1998). For example, if neighborhood effects (e.g., effects of distance to potential parent trees) are controlled for, we may expect greater genetic heterogeneity among the seed propagules in a microhabitat where the seedfall is contributed by a greater number (both individuals and species) of avian frugivores (we are advancing preliminary genetic analyses in this direction; P. Jordano, personal observation). A successful combination of careful observations of habitat use by the birds, demographic methods to characterize the seed and seedling shadows, and molecular techniques is thus required to understand these far-reaching consequences of frugivore activity for seed dispersal.

\section{Implications and perspectives}

The main differences among frugivore species that visit and disperse a plant are the frequency of visitation, the rate of fruit handling and ingestion, and the speciesspecific flight patterns and postforaging patterns of habitat use. However, even detailed knowledge of these characteristics is insufficient to adequately assess disperser effectiveness. Quality components are strongly dependent on differences among patches in seed survival, germination, and seedling survival and growth. The potential thus exists for the sequence of concatenated postdispersal events (Herrera et al. 1994, Jordano and Herrera 1995, Schupp 1995, Schupp and Fuentes 1995) to erase any initial differences imposed by variations in the quantity component of effectiveness.

Nonetheless, a thorough analysis of the quantity component of disperser effectiveness is a critical first step in understanding the intricacies of any dispersal system. In this study, the quantity component suggests a clear initial difference in importance for dispersal among the major frugivore functional groups: SD, PCSD, and PC. Because these are rather broad categories of frugivory types (i.e., the "gulper"-_masher" continuum), we may generalize that an initial categorization of species in a frugivore assemblage may best be achieved by only quantifying aspects of fruit removal and handling and of visitation. For example, in our system SD species were consistently more efficient than PCSD species, but even an inefficient PCSD species with a high frequency of visitation might show a greater quantitative effectiveness than a scarce SD visitor. An important conclusion of this study is that due to behavioral differences, considerable variation in the quantity component also exists within the apparently homogeneous group of legitimate seed dispersers (SD). The quantity component of dispersal, then, is determined by feeding and fruit handling behaviors, which 
are largely species-specific characteristics, and by visitation rate, which is partly a species-specific trait and partly a function of species abundance.

Although an analysis of the quantity component is a critical and valuable first step toward understanding disperser effectiveness, assuming that effectiveness can be measured by quantity alone can mislead more than inform (Schupp 1993). Just as a high visitation rate may compensate for low dispersal efficiency, so even small differences in quality of seed deposition might compensate for an initial quantitative difference among SD species. In this study, the large differences among species in microhabitat patterns of seed dispersal my present such a case. Previous detailed studies, either implicitly or explicitly analyzing both quantitative and qualitative components of seed dispersal systems, have dealt with parasitic mistletoes (Reid 1989, Martínez del Río et al. 1995, Larson 1996, Martínez del Río et al. 1996). Given that highly directed dispersal is required for successful mistletoe establishment, subtle differences in quality of treatment by the disperser have impacts on seedling establishment (Murphy et al. 1993). Although not specifically aimed at assessing disperser effectiveness, studies of nonparasitic trees and shrubs with more complex dispersal systems (Howe et al. 1985, Schupp et al. 1989, Howe 1990, Chávez-Ramírez and Slack 1994, Guitián et al. 1994, Herrera et al. 1994, Jordano and Herrera 1995, Martínez-Ramos and Alvarez-Buylla 1995, Wenny and Levey 1998; see review in Schupp 1993) suggest that microhabitat-specific suitabilities for seed germination, survival, and seedling emergence and establishment are so large that differences among frugivores in the quality of deposition might generally have critical consequences for the final pattern of recruitment.

\section{ACKNOWLEDGMENTS}

We deeply appreciate the help, advice, and encouragement that Luis López-Soria, Carlos M. Herrera, and the late Margarita Cobo provided. Alicia Prieto and Rocío Requerey provided helpful technical assistance. Manolo Carrión and Myriam Márquez helped us with fieldwork and support during all the stages of this study. Permission and facilities to carry out this research in the Parque Natural de las Sierras de Cazorla, Segura y Las Villas was granted by the Agencia de Medio Ambiente, Junta de Andalucía. Data collection and preliminary analyses were supported by a NSF-NATO postdoctoral fellowship and an Alexander Hollaender Distinguished Postdoctoral fellowship (Department of Energy) administered by Oak Ridge Associated Universities (to E.W. Schupp), and project PB87-0452 from the Spanish Dirección General de Investigación Científica y Técnica, Ministerio de Educación y Ciencia (P. Jordano). The final preparation of the manuscript was funded by project PB97-0142 from this agency and funds from the Consejería de Educación y Ciencia, Junta de Andalucía (both authors) and the Ecology Center and the Utah Agricultural Experiment Station, Utah State University (E.W. Schupp).

\section{Literature Cited}

Alvarez-Buylla, E. R., A. Chaos, D. Piñero, and A. A. Garay. 1996. Demographic genetics of a pioneer tropical tree spe- cies: patch dynamics, seed dispersal, and seed banks. Evolution 50:1155-1166.

Alvarez-Buylla, E. R., and M. Martínez-Ramos. 1990. Seed bank versus seed rain in the regeneration of a tropical pioneer tree. Oecologia (Berlin) 84:314-325.

Asensio, B., and L. M. Carrascal. 1990. Demography of finch populations from northern and central Europe wintering in the Iberian Peninsula: a test of the survival-fecundity hypothesis. Folia Zoologica 39:125-130.

Bairlein, F. 1981. Ökosytemanallyse der Rastplätze von Zugvögeln: Beschreibung und Deutung der Verteilungsmuster von ziehenden Kleinvögeln in verschiedenen Biotopen der Stationen des "Mettnau-Reit-Illmitz-Programmes". Ökologie der Vögel 3:7-137.

Blake, J. G., and B. A. Loiselle. 1991. Variation in resource abundance affects capture rates of birds in three lowland habitats in Costa Rica. Auk 108:114-130.

Bruederle, L. P., D. F. Tomback, K. K. Kelly, and R. C. Hardwick. 1998. Population genetic structure in a bird-dispersed pine, Pinus albicaulis (Pinaceae). Canadian Journal of Botany 76:83-90.

Carr, D. E. 1992. The relationship between crop size and fruit removal and its implication for the evolution of dioecy. Canadian Journal of Botany 70:1784-1789.

Ceballos, L., and J. Ruiz. 1979. Arboles y arbustos de la España Peninsular. Escuela Técnica Superior de Ingenieros de Montes, Madrid, Spain.

Chávez-Ramírez, F., and R. D. Slack. 1994. Effects of avian foraging and post-foraging behavior on seed dispersal patterns of Ashe juniper. Oikos 71:40-46.

Clark, D. A., and D. B. Clark. 1984. Spacing dynamics of a tropical rain forest tree: evaluation of the Janzen-Connell model. American Naturalist 124:769-788.

Clergeau, P. 1991. Rôle de la structure de la vegetation sur le recrutement de plantes ornithochores dans l'Ouest de la France. Bulletin Societé Scientifique Bretagne 62:73-90.

Cody, M. L. 1974. Competition and the structure of bird communities. Monographs in Population Biology, Number 7.

Corlett, R. T., and P. W. Lucas. 1990. Alternative seed-handling strategies in primates: seed-spitting by long-tailed macaques (Macaca fascicularis). Oecologia (Berlin) 82: $166-171$.

Davidar, P., and E. S. Morton. 1986. The relationship between fruit crop sizes and fruit removal rates by birds. Ecology 67:262-265.

Debussche, M., J. Escarre, and J. Lepart. 1982. Ornithochory and plant succession in mediterranean abandoned orchards. Vegetatio 48:255-266.

Debussche, M., and P. Isenmann. 1994. Bird-dispersed seed rain and seedling establishment in patchy mediterranean vegetation. Oikos 69:414-426.

Debussche, M., J. Lepart, and J. Molina. 1985. La dissemination des plantes à fruits charnus par les oiseaux: rôle de la structure de la vegétation et impact sur la succession en region Mediterranéenne. Acta Oecologica, Oecologia Generalis 6:65-80.

Denslow, J. S. 1987. Fruit removal rates from aggregated and isolated bushes of the red elderberry, Sambucus pubens. Canadian Journal of Botany 65:1229-1235.

Fleming, T. H., and C. F. Williams. 1990. Phenology, seed dispersal, and recruitment in Cecropia peltata (Moraceae) in Costa Rican tropical dry forest. Journal of Tropical Ecology 6:163-178.

Foster, M. S. 1987. Feeding methods and efficiencies of selected frugivorous birds. Condor 89:566-580.

Fox, G. A. 1993. Failure-time analysis: emergence, flowering, survivorship, and other waiting times. Pages 253-289 in S. M. Scheiner and J. Gurevitch, editors. Design and analysis of ecological experiments. Chapman and Hall, New York, New York, USA. 
Graham, C. H., T. C. Moermond, K. A. Kristensen, and J. Mvukiyumwami. 1995. Seed dispersal effectiveness by two bulbuls on Maesa lanceolata, an African montane forest tree. Biotropica 27:479-486.

Guitián, J. 1993. Why Prunus mahaleb (Rosaceae) produces more flowers than fruits. American Journal of Botany 80: 1305-1309.

Guitián, J., M. Fuentes, T. Bermejo, and B. López. 1992. Spatial variation in the interactions between Prunus mahaleb and frugivorous birds. Oikos 63:125-130.

Guitián, J., P. Guitián, and J. M. Sánchez. 1993. Reproductive biology of two Prunus species (Rosaceae) in the Northwest Iberian Peninsula. Plant Systematics and Evolution 185: 153-165.

Guitián, J., I. Munilla, P. Guitián, and B. López. 1994. Frugivory and seed dispersal by redwings Turdus iliacus in Southwest Iceland. Ecography 17:314-320.

Herrera, C. M. 1984. A study of avian frugivores, bird-dispersed plants, and their interaction in mediterranean scrublands. Ecological Monographs 54:1-23.

Herrera, C. M. 1988. The fruiting ecology of Osyris quadripartita: individual variation and evolutionary potential. Ecology 69:233-249.

Herrera, C. M. 1989. Frugivory and seed dispersal by carnivorous mammals, and associated fruit characteristics, in undisturbed mediterranean habitats. Oikos 55:250-262.

Herrera, C. M. 1991. Dissecting factors responsible for individual variation in plant fecundity. Ecology 72:14361448.

Herrera, C. M. 1998. Long-term dynamics of Mediterranean frugivorous birds and fleshy fruits: a 12-year study. Ecological Monographs 68:511-538.

Herrera, C. M., and P. Jordano. 1981. Prunus mahaleb and birds: the high efficiency seed dispersal system of a temperate fruiting tree. Ecological Monographs 51:203-221.

Herrera, C. M., P. Jordano, L. López Soria, and J. A. Amat. 1994. Recruitment of a mast-fruiting, bird-dispersed tree: bridging frugivore activity and seedling establishment. Ecological Monographs 64:315-344.

Holthuijzen, A. M. A., and T. L. Sharik. 1985. The avian seed dispersal system of eastern red cedar (Juniperus virginiana). Canadian Journal of Botany 63:1508-1515.

Hoppes, W. G. 1987. Pre- and post-foraging movements of frugivorous birds in an eastern deciduous forest woodland, USA. Oikos 49:281-290.

Hoppes, W. G. 1988. Seedfall pattern of several species of bird-dispersed plants in an Illinois woodland. Ecology 69: $320-329$.

Howe, H. F. 1990. Seed dispersal by birds and mammals: implications for seedling demography. Pages 191-218 in K. S. Bawa and M. Hadley, editors. Reproductive ecology of tropical forest plants. Man and the Biosphere Series. Volume 7. UNESCO and Parthenon Publishing Group, Paris, France.

Howe, H. F. 1993. Specialized and generalized dispersal systems: where does 'the paradigm' stand? Pages 3-13 in T. H. Fleming and A. Estrada, editors. Frugivory and seed dispersal: ecological and evolutionary aspects. Kluwer Academic, Dordrecht, The Netherlands.

Howe, H. F., and R. B. Primack. 1975. Differential seed dispersal of the tree Casearia nitida (Flacourtiaceae). Biotropica 7:278-283.

Howe, H. F., E. W. Schupp, and L. C. Westley. 1985. Early consequences of seed dispersal for a neotropical tree ( $\mathrm{Vi}$ rola surinamensis). Ecology 66:781-791.

Howe, H. F., and G. A. Vande Kerckhove. 1981. Removal of wild nutmeg (Virola surinamensis) crops by birds. Ecology 62:1093-1106.

Izhaki, I., P. B. Walton, and U. N. Safriel. 1991. Seed shadows generated by frugivorous birds in an eastern Mediterranean scrub. Journal of Ecology 79:575-590.

Jordano, P. 1983. Fig-seed predation and dispersal by birds. Biotropica 15:38-41.

Jordano, P. 1985. El ciclo anual de los paseriformes frugívoros en el matorral mediterráneo del sur de España: importancia de su invernada y variaciones interanuales. Ardeola 32:69-94.

Jordano, P. 1987a. Avian fruit removal: effects of fruit variation, crop size, and insect damage. Ecology 68:17111723.

Jordano, P. 1987b. Frugivory, external morphology and digestive system in mediterranean sylviid warblers Sylvia spp. Ibis 129:175-189.

Jordano, P. 1989. Pre-dispersal biology of Pistacia lentiscus (Anacardiaceae): cumulative effects on seed removal by birds. Oikos 55:375-386.

Jordano, P. 1992. Fruits and frugivory. Pages 105-156 in M. Fenner, editor. Seeds: the ecology of regeneration in plant communities. Commonwealth Agricultural Bureau International, Wallingford, UK.

Jordano, P. 1993a. Geographical ecology and variation of plant-seed disperser interactions: southern Spanish junipers and frugivorous thrushes. Pages 85-104 in T. H. Fleming and A. Estrada, editors. Frugivory and seed dispersal: ecological and evolutionary aspects. Kluwer Academic Publisher, Dordrecht, The Netherlands.

Jordano, P. 1993b. Pollination biology of Prunus mahaleb L.: deferred consequences of gender variation for fecundity and seed size. Biological Journal of the Linnean Society 50:65-84.

Jordano, P. 1994. Spatial and temporal variation in the avianfrugivore assemblage of Prunus mahaleb: patterns and consequences. Oikos 71:479-491.

Jordano, P. 1995. Frugivore-mediated selection on fruit and seed size: birds and St. Lucie's cherry, Prunus mahaleb. Ecology 76:2627-2639.

Jordano, P., and C. M. Herrera. 1995. Shuffling the offspring: uncoupling and spatial discordance of multiple stages in vertebrate seed dispersal. Écoscience 2:230-237.

Katusic-Malmborg, P., and M. F. Willson. 1988. Foraging ecology of avian frugivores and some consequences for seed dispersal in an Illinois woodlot. Condor 90:173-186.

Kollmann, J., and D. Goetze. 1997. Notes on seed traps in terrestrial plant communities. Flora 192:1-10.

Kollmann, J., and M. Pirl. 1995. Spatial pattern of seed rain of fleshy-fruited plants in a scrubland grassland transition. Acta Oecologica 16:313-329.

Kollmann, J., and P. Poschlod. 1997. Population processes at the grassland-scrub interface. Phytocoenologia 27:235256.

Kollmann, J., and B. Schneider. 1996. Effects of landscape structure on seed dispersal of fleshy-fruited species along forest edges. Bulletin of the Geobotanical Institute 63:7786

Larson, D. L. 1996. Seed dispersal by specialist versus generalist foragers: the plant's perspective. Oikos 76:113-120.

Laska, M. S., and E. W. Stiles. 1994. Effects of fruit crop size on intensity of fruit removal in Viburnum prunifolium (Caprifoliaceae). Oikos 69:199-202.

Levey, D. J. 1986. Methods of seed processing by birds and seed deposition patterns. Pages 147-158 in A. Estrada and T. H. Fleming, editors. Frugivores and seed dispersal. Dr. W. Junk, Dordrecht, The Netherlands.

Levey, D. J. 1987. Seed size and fruit-handling techniques of avian frugivores. American Naturalist 129:471-485.

Loiselle, B. A., and J. G. Blake. 1993. Spatial distribution of understory fruit-eating birds and fruiting plants in a neotropical lowland wet forest. Pages 177-189 in T. H. Fleming, and A. Estrada, editors. Frugivory and seed dispersal: 
ecological and evolutionary aspects. Kluwer Academic, Dordrecht, The Netherlands.

Loiselle, B. A., E. Ribbens, and O. Vargas. 1996. Spatial and temporal variation of seed rain in a tropical lowland wet forest. Biotropica 28:82-95.

Loiselle, B., V. L. Sork, J. Nason, and C. Graham. 1995. Spatial genetic structure of a tropical understory shrub, Psychotria officinalis (Rubiaceae). American Journal of Botany 82:1420-1425.

Mack, A. L. 1995. Distance and non-randomness of seed dispersal by the dwarf cassowary Casuarius bennetti. Ecography 18:286-295.

Manly, B. F. J. 1991. Randomization and Montecarlo methods in biology. Chapman and Hall, London, UK.

Martin, T. E., and J. R. Karr. 1986. Patch utilization by migrating birds: resource oriented? Ornis Scandinavica 17: $165-174$

Martínez del Río, C., M. Hourdequin, A. Silva, and R. Medel. 1995. The influence of cactus size and previous infection on bird deposition of mistletoe seeds. Australian Journal of Ecology 20:571-576.

Martínez del Río, C., A. Silva, R. Medel, and M. Hourdequin. 1996. Seed dispersers as disease vectors: bird transmission of mistletoe seeds to plant hosts. Ecology 77:912-921.

Martínez-Ramos, M., and E. R. Alvarez-Buylla. 1995. Seed dispersal and patch dynamics in tropical rainforests: a demographic approach. Écoscience 2:223-229.

Martínez-Ramos, M., and A. Soto. 1993. Seed rain and advanced regeneration in a tropical rain forest. Pages 299318 in T. H. Fleming and A. Estrada, editors. Frugivory and seed dispersal: ecological and evolutionary aspects. Kluwer Academic, Dordrecht, The Netherlands.

McDiarmid, R. W., R. E. Ricklefs, and M. S. Foster. 1977. Dispersal of Stemmadennia donnell-smithii (Apocyanaceae) by birds. Biotropica 9:9-25.

McDonnell, M. J., and E. W. Stiles. 1983. The structural complexity of old field vegetation and the recruitment of bird-dispersed plant species. Oecologia (Berlin) 56:109116.

Muenchow, G. 1986. Ecological use of failure time analysis. Ecology 67:246-250.

Murphy, S. R., N. Reid, Z. G. Yan, and W. N. Venables. 1993. Differential passage time of mistletoe fruits through the gut of honeyeaters and flowerpeckers-effects on seedling establishment. Oecologia 93:171-176.

Murray, K. G. 1988. Avian seed dispersal of three neotropical gap-dependent plants. Ecological Monographs 58:271298.

Obeso, J. R. 1987. Comunidades de passeriformes en bosques mixtos de altitudes medias de la Sierra de Cazorla. Ardeola 34:37-59.

Press, W. H., S. A. Teukolski, W. T. Vetterling, and B. P. Flannery. 1992. Numerical recipes in FORTRAN. Cambridge University Press, Cambridge, UK.

Reid, N. 1987. Safe sites for Amyema quandang (Lindl.) Van Tiegh (Loranthaceae) seeds: dispersal requirements and post-dispersal mortality. Pages 691-699 in H. C. Weber and W. Forstreuter, editors. Parasitic flowering plants. Proceedings of the Fourth International Symposium on Parasitic Flowering Plants, Marburg, West Germany.

Reid, N. 1989. Dispersal of mistletoes by honeyeaters and flowerpeckers: components of seed dispersal quality. Ecology 70:137-145.

Sallabanks, R. 1992. Fruit fate, frugivory, and fruit characteristics: a study of the hawthorn, Crataegus monogyna (Rosaceae). Oecologia 91:296-304.

Sallabanks, R. 1993. Hierarchical mechanisms of fruit selection by an avian frugivore. Ecology 74:1326-1336.
Sargent, S. 1990. Neighborhood effects on fruit removal by birds: a field experiment with Viburnum dentatum (Caprifoliaceae). Ecology 71:1289-1298.

Sargent, S. 1995. Seed fate in a tropical mistletoe: the importance of host twig size. Functional Ecology 9:197-204.

SAS Institute. 1988. SAS/STAT users guide. Release 6.03 edition. SAS Institute, Cary, North Carolina, USA.

Schupp, E. W. 1988. Seed and early seedling predation in the forest understory and in treefall gaps. Oikos 51:71-78.

Schupp, E. W. 1993. Quantity, quality, and the effectiveness of seed dispersal by animals. Pages 15-29 in T. H. Fleming and A. Estrada, editors. Frugivory and seed dispersal: ecological and evolutionary aspects. Kluwer Academic, Dordrecht, The Netherlands.

Schupp, E. W. 1995. Seed-seedling conflicts, habitat choice, and patterns of plant recruitment. American Journal of Botany 82:399-409.

Schupp, E. W., and M. Fuentes. 1995. Spatial patterns of seed dispersal and the unification of plant population ecology. Écoscience 2:267-275.

Schupp, E. W., H. F. Howe, C. K. Augspurger, and D. J. Levey. 1989. Arrival and survival in tropical treefall gaps. Ecology 70:562-564.

Snow, B. K., and D. W. Snow. 1988. Birds and berries. T. and A. D. Poyser, Calton, UK.

Sun, C., A. R. Ives, H. J. Kraeuter, and T. C. Moermond. 1997. Effectiveness of three turacos as seed dispersers in a tropical montane forest. Oecologia 112:94-103.

Trainer, J. M., and T. C. Will. 1984. Avian methods of feeding on Bursera simaruba (Burseraceae) fruits in Panama. Auk 101:193-195.

Traveset, A. 1994. Influence of type of avian frugivory on the fitness of Pistacia terebinthus. Evolutionary Ecology 8:618-627.

Valle, F., F. Gómez, F. Mota, and C. Díaz. 1989. Parque Natural de Cazorla, Segura y Las Villas. Guía botánico-ecológica. Editorial Rueda, Madrid, Spain.

Verdú, M., and P. García-Fayos. 1996. Nucleation processes in a mediterranean bird-dispersed plant. Functional Ecology 10:275-280.

Webb, D. A. 1968. Prunus L. Pages 77-80 in T. G. Tutin, V. H. Heywood, N. A. Burges, D. M. Moore, D. H. Valentine, S. M. Walters, and D. A. Webb, editors. Flora Europaea. Volume 2. Cambridge University Press, Cambridge, UK.

Webb, S. L., and M. F. Willson. 1985. Spatial heterogeneity in post-dispersal predation on Prunus and Uvularia seeds. Oecologia (Berlin) 67:150-153.

Wenny, D. G., and D. J. Levey. 1998. Directed seed dispersal by bellbirds in a tropical cloud forest. Proceedings of the National Academy of Sciences (USA) 95:6204-6207.

Wheelwright, N. T. 1991. How long do fruit-eating birds stay in the plants where they feed? Biotropica 23:29-40.

Willson, M. F. 1992. The ecology of seed dispersal. Pages 61-86 in M. Fenner, editor. Seeds: the ecology of regeneration in plant communities. Commonwealth Agricultural Bureau International, Wallingford, UK.

Willson, M. F. 1993. Dispersal mode, seed shadows, and colonization patterns. Pages 261-280 in T. H. Fleming and A. Estrada, editors. Frugivory and seed dispersal: ecological and evolutionary aspects. Kluwer Academic, Dordrecht, The Netherlands.

Willson, M. F., E. A. Porter, and R. S. Condit. 1982. Avian frugivore activity in relation to forest light gaps. Caribbean Journal of Science 18:1-4.

Willson, M. F., and C. J. Whelan. 1990. Variation in postdispersal survival of vertebrate-dispersed seeds: effects of density, habitat, location, season, and species. Oikos 57: 191-198. 